\title{
Narcissism and fame: a complex network model for the adaptive interaction of digital narcissism and online popularity
}

\author{
Fakhra Jabeen ${ }^{*} \mathbb{D}$, Charlotte Gerritsen and Jan Treur
}

\author{
*Correspondence: \\ fakhraikram@yahoo.com \\ Social Al Group, Vrije \\ Universiteit Amsterdam, \\ Amsterdam, Netherlands
}

\begin{abstract}
Social media like Twitter or Instagram play the role of fertile platforms for self-exhibition and allow their users to earn a good repute. People higher in grandiosity share their contents in a charismatic way and as a result, they are successful in gaining attention from others, which may also influence their responses and behaviors. Such attention and repute enable them to be a trendsetter or a socially recognized maven. In this paper, we present a complex adaptive mental network model of a narcissist to see how popularity can adaptively influence his/her behavior. To analyze and to support behavior showed by our model, we used some key performance indicators from the literature to study the popularity and narcissism of 30 Instagram profiles. The results of the-both computational and empirical — study indicate that our presented computational adaptive network model in general shows the behavior found from the empirical data.
\end{abstract}

Keywords: Digital narcissism, Digital reputation, Popularity influence, Complex network

\section{Introduction}

Narcissism reflects a personality trait which relates to a certain cluster of human behaviors, which display self-superiority and self-exhibition. These behaviors mostly relate to entitlement seeking and having a messiah complex. Narcissists need admiration and dwell for their own appearance and achievement, which often leads to lack of empathy for others (Bushman and Baumeister 1998; Fan et al. 2011). Social media platforms can help narcissists to achieve popularity and have a feeling of worth for themselves, but this can also increase their vulnerability due to the pervasive nature of social media (Bushman and Baumeister 1998). Different artificial intelligence (AI) techniques were used to detect narcissism from text analysis (Holtzman et al. 2019; Neuman 2016). Also, there are very limited computational studies addressing these behaviors. Moreover, how popularity can influence such behavior was not studied yet in more depth. Extending the preliminary (Jabeen et al. 2019), the current paper addresses this.

The new level of connectivity through social media, provides a new way to become popular. Therefore, media such as Facebook, Twitter or Instagram can act as new

(c) The Author(s) 2020. Open Access This article is licensed under a Creative Commons Attribution 4.0 International License, which permits use, sharing, adaptation, distribution and reproduction in any medium or format, as long as you give appropriate credit to the original author(s) and the source, provide a link to the Creative Commons licence, and indicate if changes were made. The images or other third party material in this article are included in the article's Creative Commons licence, unless indicated otherwise in a credit line to the material. If material is not included in the article's Creative Commons licence and your intended use is not permitted by statutory regulation or exceeds the permitted use, you will need to obtain permission directly from the copyright holder. To view a copy of this licence, visit http:// creativecommons.org/licenses/by/4.0/. 
channels for self-promotion of a narcissist. They share proactive materials like selfies (Holtzman et al. 2010), or posts with their lifestyle information, which makes them dominant (Alshawaf and Wen 2015). Previous studies explained that there is a relationship between narcissism, excessive usage of social media (McCain and Campbell 2018; Panek et al. 2013) and reward-seeking behavior (Bushman and Baumeister 1998). In a preliminary version of our work, we presented a complex second-order adaptive network model that explains the reactions of a narcissist in case of positive and negative feedback (Jabeen et al. 2019). However, it is also interesting to see how popularity can influence these reactions; this addition is contributed by the current paper, as is a much more extensive empirical study involving 30 social media profiles.

More specifically, in this paper, in addition to network-oriented computational modeling of narcissist behaviour, we address both empirically and computationally (a) how a presumed narcissist earns popularity over time, and (b) how popularity can influence his/her behavior. The paper is organized as follows. In "State of the art literature" section, we discuss the state-of-the-art literature related to narcissistic behaviors, along with popularity over social media. "Methods and methodologies and the obtained adaptive network model" section presents the method and methodologies applied and the obtained adaptive network model. In "Simulation experiments" section simulation results are presented. "Analysis of simulation experiments with reference to real-world data" section discusses how behaviors from real-world relates to the designed computational model, through 30 public Instagram profiles. "Limitations and future work" section discusses the limitations and future work options of the study and "Conclusion" concludes the paper.

\section{State of the art literature}

This section presents the related work in two streams: i.e. firstly, it discusses the psychological and neurological aspects of a narcissistic person and his/her expected behaviors. Secondly, it presents the influence of digital reputation over such behaviors. At the end of the section, AI-based approaches are also discussed, which were used to predict a narcissist.

\section{Narcissism}

Narcissism is characterized by the mythological figure Narcissus, who passionately fell in love with his own reflection (Brummelman et al. 2015). This complex phenomenon of acute concern of self-admiration can be described in terms of psychological, cognitive, and social processes.

Psychologically, narcissists show a high tendency for self-admiration and self-presentation (Wang 2017). A study indicated that there is a strong association between narcissism and reward-seeking behavior (Bushman and Baumeister 1998). Social media like Instagram is a well-known platform used for self-exhibition (Alshawaf and Wen 2015). A narcissist may receive a compliment and react with kindness and joy (Moon et al. 2016) as an outcome of reward-seeking behavior (Fan et al. 2011), or with a non-empathetic response to a critic (Bushman and Baumeister 1998; Fan et al. 2011).

In cognitive neurological sciences, different brain parts interact with each other for an interpretation and response to feedback. For example, the prefrontal cortex (PFC) 
along with the Anterior Insula and temporal lobe evaluates feedback as a compliment (Olsson et al. 2014). As a result, activations in the anterior cingulate cortex (ACC) along with the ventral striatum show the reward-seeking behavior. Different hormones and neurotransmitters also take part when a person is admired. For example, dopamine is released when a narcissist feels that his target of sharing content is achieved, as (s)he is admired (Daniel and Pollmann 2014). Similarly, $\gamma$-aminobutyric acid (GABA) receptors are activated, due to anxiety, which results from a negative evaluation of a critic (Sun et al. 2016). This negative evaluation leads to a threat to his/her ego as (s)he feels socially rejected (Bushman and Baumeister 1998). The hippocampus in the brain is affected by psychological stress, which affects, in particular, the memory and the learning capabilities by decreased synaptic plasticity (Schmidt et al. 2013; Sun et al. 2016). This reduction in synaptic plasticity is due to changes in the brain structure caused by stress (Sun et al. 2016). Also, cortisol levels are elevated when a person feels stress (Jauk et al. 2017).

\section{Popularity}

Narcissists use social media excessively, to display their charismatic looks and, by their social skills, they can become social mavens or influencers (Moon et al. 2016). Instagram is an ideal platform for an individual to engage him/herself and to gain more visibility. This process of self-promotion involves the visual appearance of a person with a high number of followers who talk about his/her likability (Holtzman et al. 2010) and, digital reputation is earned (Alshawaf and Wen 2015). They proactively gear themselves and their followers, to increase the follower likability and engagement (Bernarte et al. 2015). An example of such behavior can be a selfie with lifestyle information (Alshawaf and Wen 2015), captioned by using hashtags (Page 2012). Often, they follow limited people and, thus, have a high follower to following ratio, indicating their high influence/popularity (Farwaha and Obhi 2019; Garcia et al. 2017). A study also indicated that high numbers of likes can indicate how popular the posts of a person are (Chua and Chang 2016). High popularity may leave a positive impact and give personal satisfaction, along with the sense of achievement (Nesi and Prinstein 2015; Trent 1957).

Among AI-based approaches, a study related to machine learning tried to detect narcissism from text, where text as a vector was compared with personality vectors or dimensions resulting patterns of narcissism in psychological dimension (Neuman 2016). Another textual analysis approach (LIWC) used first-person singular pronouns to detect narcissism (Holtzman et al. 2019). In our previous work, we discussed the vulnerable behavior of a narcissist through a complex network model (Jabeen et al. 2019). Here, we extend our work by studying popularity and its influence on the responses/behavior of a narcissist.

\section{Methods and methodologies and the obtained adaptive network model}

Causal network modeling is a well-known approach in the field of artificial intelligence, which is helpful in making predictions about the behaviors of a person or a real-world scenario. Variables in a causal model, act as basic building blocks to represent the occurrence of an event (e.g. "he graduated"), which leads to behavioral changes in a system or a person (e.g. "he got admission") (Scheines et al. 1991). Temporal-causal network modeling distinguishes itself from static causal network 
modeling, by adding a temporal perspective on causality. In addition, adaptive temporal-causal network modeling also addresses that network connections and other network characteristics can change over time. It is applicable to design and simulate a variety of models related to many domains like neural, mental, biological, social network, and many others. This section describes the adaptive temporal-causal network modeling approach using a multilevel reified network architecture (Treur 2020), which was used to design our model.

A reified network architecture is a multilevel network architecture, in which a temporal causal network is presented at the base level and the adaptiveness of the network is represented at (higher) reification levels. The base level contains a causal network representation, specified by a directed graph having 'states' as vertices and, 'connections' as edges between them. To illustrate this, consider a connection: $X \rightarrow Y$. This indicates that state $Y$ is influenced by state $X$. The activation level of $Y$ is computed through a combination function, which uses the aggregated causal impact by all states including $X$, from which $Y$ has incoming connections. The aggregated causal impact depends on the connection weights and the activation levels of the incoming states. Therefore, for each state $Y$ we have a:

- Connection weight $\boldsymbol{\omega}_{X, Y}$ : how strong state $X$ can influence state $Y$. The magnitude normally varies between 0 and 1 , but suppression from a state is specified by a negative connection weight.

- Speed factor $\boldsymbol{\eta}_{Y}$ : how fast state $Y$ is influenced by the impact of incoming states. The range is normally between low: 0 and high: 1 .

- Combination function $\mathbf{c}_{Y}(.$.$) : used to determine the aggregated impact of all states$ with incoming connections to $Y$. Either an existing combination functions can be used like: the identity function, the advanced logistic sum function, and so on, or a custom function can be defined.

The above introduced $\omega_{X, Y}, \eta_{Y}$ and $c_{Y}(.$.$) are the network characteristics defining a$ temporal-causal network model. An adaptive network model occurs when such characteristics are dynamic and change over time. The adaptiveness of the base level network considered here is represented by first-order adaptation principles (modeled at level II) and second-order adaptation principles (modeled at level III). An $n$ th-order adaptive network model is specified by declarative specifications of an $n+1$ leveled network design and can be represented mathematically as shown in "Appendix A". Here, it is shown how a (three leveled) second-order reified adaptive network architecture was designed to address the complex adaptive mental network model of a narcissist.

\section{Level I: the base network level}

This section addresses the base network model (Level I) of a narcissist depicting his mental organization by 39 states (Fig. 1). A categorical explanation of each state is presented in Table 1. A state can have three types of incoming connections:

- Black arrows for a positive connection with weight values between $(0,1]$. 


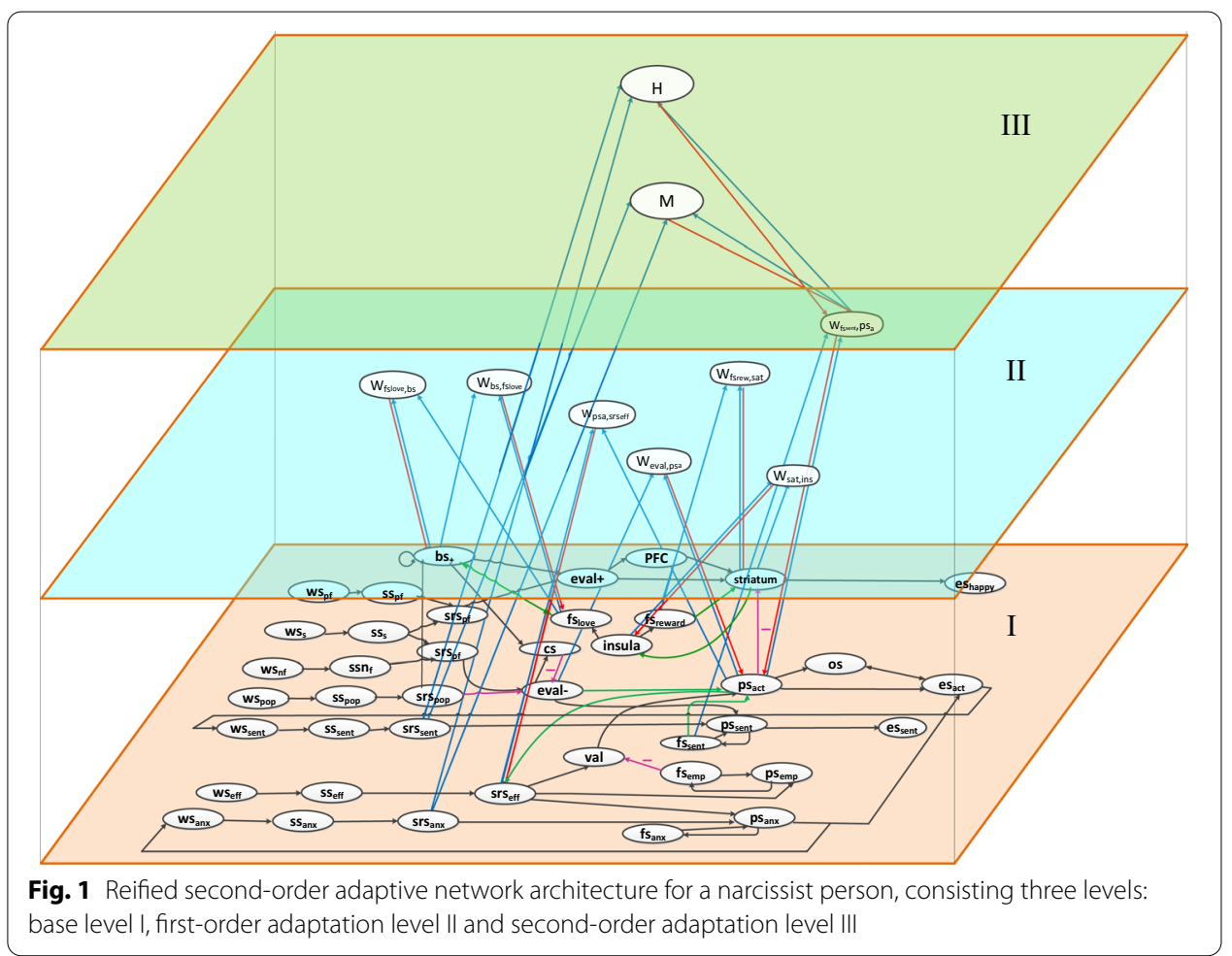

- Purple arrows for a negative connection with weight values between $[-1,0]$.

- Green arrows show the adaptive connections which lead to an adaptive behavior and will be explained further in "Level II and III: the adaptation levels" section.

The model has three inputs from surroundings: $\mathrm{ws}_{\mathrm{pf}}, \mathrm{ws}_{\mathrm{nf}}$ and $\mathrm{ws}_{\mathrm{s}}$. State $\mathrm{ws}_{\mathrm{pf}}$ shows the positive, while $\mathrm{ws}_{\mathrm{nf}}$ represents the negative feedback from another peer. State $\mathrm{ws}_{\mathrm{s}}$ represents the stimulus, for example, the usage of social media. Three output states: es $_{\text {happy' }}$ $\mathrm{es}_{\mathrm{act}}$, and $\mathrm{es}_{\text {sent }}$ represent the reaction of a narcissist. State $\mathrm{es}_{\text {happy }}$ is an outcome when the person receives positive feedback $\left(\mathrm{ws}_{\mathrm{pf}}=1, \mathrm{ws}_{\mathrm{nf}}=0\right)$ and $\mathrm{es}_{\mathrm{act}}$ and $\mathrm{es}_{\text {sent }}$ are the outcomes for a critic received $\left(\mathrm{ws}_{\mathrm{pf}}=0, \mathrm{ws}_{\mathrm{nf}}=1\right)$.

When a narcissist shares an attractive post (e.g. his/her selfie with an attractive caption) over social media, he often receives different types of feedback from others. A result of feedback like 'you are awesome' makes him/her feel happy and loved. Based upon the narcissus mythology, here his/her self-belief (bs+) evaluates such feedback as positive (eval+). Therefore, the mental states related to self-enhancement (PFC; Insula) are activated, along with the reward-seeking states: striatum, feelings of self-love ( $\left.\mathrm{fs}_{\text {love }}\right)$ and reward $\left(\mathrm{fs}_{\mathrm{rew}}\right)$. The feelings of self-love increase the esteem/self-belief state $\left(\mathrm{bs}_{+}\right)$ over time, which escalates his or her reward-seeking behavior, making him/her a narcissistic soul.

A narcissist person usually disagrees to a critic due to high ego/self-belief. So, his/her negative feelings arise when $\mathrm{ws}_{\mathrm{nf}}=1$, which may result in a non-empathetic/negative response. To explain it further, a remark like 'you are ugly', will be evaluated (eval-) as negative, and can provoke a response like 'go off you loser'. Here, ego/self-belief (bs+) 
Table 1 Categorical explanation of states of base network (level I)

\begin{tabular}{|c|c|c|}
\hline \multicolumn{2}{|l|}{ Categories } & \multirow{3}{*}{$\begin{array}{l}\text { References } \\
\text { "the representation of the world external to the } \\
\text { body can come into the brain only via the } \\
\text { body itself" (Damasio 2012) }\end{array}$} \\
\hline$\underline{\text { Stimulus states }}$ & & \\
\hline$\overline{W_{i}}$ & $\begin{array}{l}\text { World state. } i=\text { stimulus s; posi- } \\
\text { tive/negative feedback (pf/nf) }\end{array}$ & \\
\hline $\mathrm{SS}_{i}$ & Sensory state. $i=$ stimulus; pf/nf & \\
\hline $\mathrm{srs}_{i}$ & Representation state $j=\mathrm{pf} / \mathrm{nf}$ & \\
\hline \multicolumn{2}{|l|}{$\underline{\text { Attribution/evaluation states }}$} & "Narcissism involves states for self-enhance- \\
\hline eval+ & Positive evaluation of feedback & ment and mentalizing" (Olsson et al. 2014) \\
\hline eval- & Negative evaluation of feedback & \\
\hline \multicolumn{2}{|l|}{ Happiness related states } & "fMRI studies show activations at or near \\
\hline $\mathrm{bs}_{+}$ & Self-belief state & dopaminergic midbrain nuclei and the VS \\
\hline striatum & Ventral Striatum: brain part & $\begin{array}{l}\text { that correlate with both reward expectation } \\
\text { and reward prediction errors..."(Daniel and }\end{array}$ \\
\hline PFC & Prefrontal cortex: brain part & Pollmann 2014) \\
\hline $\mathrm{fS}_{\text {reward }}$ & Feeling state of reward (Amygdala) & \\
\hline $\mathrm{fS}_{\text {love }}$ & Feeling state self-love (Amygdala) & \\
\hline es happy & Execution state of happiness & \\
\hline insula & Anterior Insula: brain part & \\
\hline \multicolumn{2}{|l|}{$\underline{\text { Sentiment related action states }}$} & "mind is informed of the actions taken.. the \\
\hline os & Ownership state & \\
\hline $\mathrm{ps}_{\mathrm{act}}$ & Preparation state of action & our self' (Damasio 2012) \\
\hline $\mathrm{es}_{\mathrm{act}}$ & Execution state of action & \\
\hline \multicolumn{2}{|c|}{ Body loops: sentiment (sent) and anxiety (anx) } & "The as-if body loop hypothesis entails that \\
\hline $\mathrm{WS}_{i}$ & World state for $i=$ sent/anx & $\begin{array}{l}\text { the brain structures in charge of triggering } \\
\text { a particular emotion be able to connect to }\end{array}$ \\
\hline $\mathrm{SS}_{i}$ & Sensor state $i=$ sent/anx & the structures in which the body state corre- \\
\hline $\mathrm{ps}_{i}$ & Preparation state for $i=$ sent/anx & sponding to the emotion would be mapped." \\
\hline $\mathrm{fS}_{i}$ & Feeling state for $i=$ sent/anx & \\
\hline $\mathrm{es}_{\text {sent }}$ & Execution state of sentiment & \\
\hline \multicolumn{2}{|l|}{ Predicted effect of action } & \multirow{4}{*}{$\begin{array}{l}\text { "They need to know that this person will listen } \\
\text { to their fears, take them seriously and do } \\
\text { something" (Elliott 2002) }\end{array}$} \\
\hline$W_{\text {eff }}$ & World state of effect & \\
\hline $\mathrm{SS}_{\text {eff }}$ & Sensor state of effect & \\
\hline $\mathrm{srs}_{\mathrm{eff}}$ & Representation state of effect & \\
\hline \multicolumn{2}{|l|}{$\underline{\text { Control states }}$} & \multirow{3}{*}{$\begin{array}{l}\text { "the survival intention of the eukaryotic cell } \\
\text { and the survival intention implicit in human } \\
\text { consciousness are one and the same". } \\
\text { (Damasio 2012) }\end{array}$} \\
\hline CS & Control state & \\
\hline val & Valuation state & \\
\hline \multicolumn{2}{|l|}{ Popularity } & \multirow{4}{*}{$\begin{array}{l}\text { "popularity moderated ... depressive symp- } \\
\text { toms." (Nesi and Prinstein 2015) }\end{array}$} \\
\hline$W_{\text {pop }}$ & World state of effect & \\
\hline $\mathrm{SS}_{\mathrm{pop}}$ & Sensor state of effect & \\
\hline $\mathrm{srs}_{\mathrm{pop}}$ & Representation state of effect & \\
\hline
\end{tabular}

initially tries to suppress this evaluation through control state (cs). However, evaluataion (eval-) is too strong to be suppressed, resulting, (a) stimulation of negative sentiments and (b) a non-empathic reaction to the peer.

Here, we address two categories of negative sentiments/feelings by the sentiment body loop ( $\mathrm{ws}_{\text {sent }} ; \mathrm{ss}_{\mathrm{sent}} ; \mathrm{srs}_{\text {sent }} ; \mathrm{fs}_{\text {sent }} ; \mathrm{ps}_{\text {sent }} ; \mathrm{es}_{\text {sent }}$ ): negative and extreme negative (Ntshangase 2018). The negative feelings are the low-intensity feelings like: fear, sadness or rejection. While the extreme/very negative feelings, are the ones with a high intensity such as of anger, humiliation, rage or frustration. Action ( $\left.\mathrm{ps}_{\mathrm{act}} ; \mathrm{es}_{\mathrm{act}}\right)$, is an aggregate result of negative feelings $\left(\mathrm{fs}_{\text {sent }}\right)$, evaluation (eval-) and valuation (val) states. This may result in a 
response like "back off" or deleting and block that peer. It is to be noted, that the valuation state (val) in principle doesn't get activated if the person has empathy ( $\mathrm{fs}_{\mathrm{emp}} ; \mathrm{ps}_{\mathrm{emp}}$ ), which is not the case here (as he/she is narcissist (Fan et al. 2019). After activation of $\mathrm{ps}_{\text {act, }}$ the thought process related to ownership state (os) and predicted effect ( $\mathrm{ws}_{\mathrm{eff}}$; $\mathrm{ss}_{\mathrm{eff}}$; $\left.\mathrm{srs}_{\text {eff }}\right)$ is also activated, which induces anxiety $\left(\mathrm{ws}_{\mathrm{anx}} ; \mathrm{ss}_{\mathrm{anx}} ; \mathrm{srs}_{\mathrm{anx}} ; \mathrm{fs}_{\mathrm{anx}}\right.$ and $\left.\mathrm{ps}_{\mathrm{anx}}\right)$. The body loop of anxiety differs from the body loop of sentiments (Raghunathan and Pham 1999; Weger and Sandi 2018), as it can elevate such reactions ( $\left.\mathrm{es}_{\mathrm{act}}\right)$ along with experience/learning from the actions ( $\left.\mathrm{ps}_{\mathrm{act}}\right)$.

Popularity ( $\mathrm{ws}_{\mathrm{pop}}$; $\mathrm{ss}_{\mathrm{pop}}$; $\mathrm{srs}_{\mathrm{pop}}$ ) serves as a moderator to these negative feelings. Thus, popularity lowers the negative evaluation (eval-), negative sentiments and feelings of anxiety(Nesi and Prinstein 2015), so the negative outcomes appear less than before (discussed in "Level II and III: the adaptation levels" section).

\section{Level II and III: the adaptation levels}

The reified network architecture used for our network model has two adaptation levels represented by first- (Level II) and second-order (Level III) adaptation (see Fig. 1). The first-order adaptation level (Level II) relates to the ability to learn/adapt certain behavior(s) by experience over time (for example: with age/popularity) known as neuroplasticity or hebbian plasticity/hebbian learning. In this case, connections in the base network appear not to be fixed in terms of their weights and may change over time (shown by green arrows at Level I). In our model, this change due to hebbian learning principle is modeled by seven reification states: 'W-states' at Level II (also see Table 2). The second-order adaptation level (Level III) addresses the adaptation of W-states, which represents plasticity of neuroplasticity or metaplasticity (Robinson et al. 2016; Schmidt et al. 2013). It is modeled by adaptive persistence factor $\boldsymbol{\mu}$ and adaptive learning rate $\boldsymbol{\eta}$ by reification states $\mathbf{M}$ and $\mathbf{H}$ respectively at Level III. This shows how synaptic transmission can be influenced and controlled by other factors, for example, through hormones or neurotransmitters (Robinson et al. 2016; Treur 2020, Ch. 4).

In Fig. 1, the inter-level interactions are represented by two types of arrows: red (downward) and blue (upward). The red arrows show the specific causal impact from reification states to a certain state, while the blue arrows are used to create and represent

Table 2 Explanation of states in level II and III

\begin{tabular}{|c|c|c|}
\hline \multicolumn{2}{|l|}{ States per level } & \multirow[t]{2}{*}{ References } \\
\hline Level II (plasticity/omega states) & & \\
\hline 1. $\mathbf{W}_{\mathrm{fs}_{\text {love }}, \mathrm{bs}}$ & For $\mathrm{fs}_{\text {love }} \rightarrow \mathrm{bs}$ & depends not only on strong pre-and \\
\hline 2. $\mathbf{W}_{\mathrm{bs}, \mathrm{fs}_{\text {love }}}$ & For bs $\rightarrow \mathrm{fs}_{\text {love }}$ & prediction ... modify behavior (Dan- \\
\hline 3. $\mathbf{W}_{\text {sat,ins }}$ & For striatum $\rightarrow$ insula & iel and Pollmann 2014) \\
\hline 4. $\mathbf{W}_{\text {fsrew, striatum }}$ & For $\mathrm{fS}_{\text {reward }} \rightarrow$ striatum & $\begin{array}{l}\text { 5-7: Presynaptic somatodendritic } \\
\text { 5-HT1... people with a high level of }\end{array}$ \\
\hline 5. $\mathbf{W}_{\mathrm{eval}-, \mathrm{ps}_{\mathrm{a}}}$ & For eval- $\rightarrow \mathrm{ps}_{\text {act }}$ & aggression, there is a greater density \\
\hline 6. $\mathbf{W}_{\mathrm{ps}_{\mathrm{act}}, \mathrm{srs}_{\mathrm{eff}}}$ & For $\mathrm{ps}_{\mathrm{act}} \rightarrow \mathrm{srs}_{\mathrm{eff}}$ & ... with impulse control (de Almeida \\
\hline 7. $\mathbf{W}_{\mathrm{fs}_{\text {sent, }}, \mathrm{ps}_{\mathrm{a}}}$ & For $\mathrm{fs}_{\text {sent }} \rightarrow \mathrm{ps}_{\mathrm{act}}$ & et al. 2015) \\
\hline Level III (meta-plasticity) & & Damage to neurons in hippocampal \\
\hline $\mathrm{H}$ & Speed factor for $\mathbf{W}_{\text {fsang,psa }}$ & CA3 are and microstructure of syn- \\
\hline M & Persistance factor for $\mathbf{W}_{\text {fsang,psa }}$ & plasticity .... (Sun et al. 2016) \\
\hline
\end{tabular}


the dynamics of the reification states on the higher levels. For illustration, consider when a person receives negative feedback, ( $\mathrm{s})$ he reacts $\left(\mathrm{ps}_{\mathrm{act}} ; \mathrm{es}_{\mathrm{act}}\right)$ after having a negative sentiment about the feedback (connection: eval $-\rightarrow \mathrm{ps}_{\mathrm{act}}$ ). The way of reacting after such a feeling is learnt from personal experience. This can be modeled by hebbian learning at Level II. To model Hebbian learning, reification state $\mathbf{W}_{\text {eval-,ps act }}$ receives an impact from the pre-synaptic and post-synaptic states, i.e. eval- (relating to stress-related cortisol levels) and $\mathrm{ps}_{\text {act }}$, this $\mathbf{W}_{\text {eval-,ps }}$ in turn affects the post-synaptic state $\mathrm{ps}_{\text {act }}$, making it a form of circular causation. Similarly, when a positive feedback is evaluated ( $\mathrm{fs}_{\text {reward }}$ relating to dopamine release), this affects $\mathbf{W}_{\mathrm{fs}_{\mathrm{r} e w} \text {,striatum }}$, with respective pre-synaptic $\left(\mathrm{fs}_{\text {reward }}\right)$ and post-synaptic (striatum) states. A similar pattern of interlevel connections can be observed for Level III. Here, metaplasticity states $\mathbf{H}$ and $\mathbf{M}$ receive the respective input from the pre-synaptic ( $\left.\mathrm{srs}_{\text {sent }} ; \mathrm{srs}_{\mathrm{anx}}\right)$ and post-synaptic $\left(\mathrm{ps}_{\mathrm{act}}\right)$ states, represented in Fig. 1 by blue upward arrows. These states are related to meta-adaptation, which controls (red arrows from $\mathbf{M}$ and $\mathbf{H}$ to $\mathbf{W}_{\mathrm{fs}_{\text {sent }}, \mathrm{ps}_{\mathrm{a}}}$ ) the learning and the speed of the state $\mathbf{W}_{\mathrm{fs}_{\mathrm{sent}}, \mathrm{ps}_{\mathrm{ac}}}$ at Level II (Schmidt et al. 2013; Sun et al. 2016).

A network model can be simulated using the reified network engine designed in MAT$\mathrm{LAB}$, by providing a declarative specification in the form of role matrices. A role matrix is a compact specification by the concept of the role played by a state (Treur 2020, Ch. 9). For example, base network matrix (mb) enlists all the states with incoming connections to any state. Similarly, connection weight matrix (mcw) and speed matrix (ms) provide the connection weights and speed factor for each state. The combination function weight (mcfw) and combination function parameter matrix (mcfp) specify combination functions with their weights, and parameters respectively. Role matrices provide a declarative specification of the adaptive network model. The full specification of the adaptive network model in terms of role matrices can be found online (Jabeen 2020).

\section{Simulation experiments}

By simulation experiments the dynamics of the designed adaptive network model can be explored through simulating real-world scenarios. In this section, we present different simulations. First, we will see the two reactions of a narcissist i.e. a happy reaction or a reaction expressing annoyance. Second, we will see how a person gains popularity over social media and how it will influence both of his/her reactions. Third, we will see how a person reacts, when (s)he loses popularity. Therefore, this section is divided into two subsections (a) reactions to a feedback and (b) influence of popularity on the reactions.

\section{Reactions to feedback}

Here, we present our two scenarios; i.e. with: (a) a positive reaction or, (b) a negative reaction, along with few example tweets of Donald Trump, who is studied as a 'narcissistic', and to have a 'messiah complex' (Nai 2019).

\section{Reacting a positive feedback}

Social media like Facebook, Twitter, or Instagram is a platform, where self-confidence of a narcissist speaks by itself (Moon et al. 2016; Wang 2017). For example, the following tweet of Trump: 
...my two greatest assets ... mental stability and being, like, really smart ... I went from VERY successful businessman, to top TV Star... (Tweeted: 1:27 PM - Jan 6, 2018).

Figure 2 shows the simulation results; here the horizontal axis shows the time scale and, the vertical axis shows the dynamic state values $([0,1])$ over time. As positive feedback is received $\left(\mathrm{ws}_{\mathrm{pf}}=1\right)$, the state eval+ (purple) is activated, which in turn activates the state PFC (golden) around time point $t \approx 5-10$. These two activations along with bs+ ( brown), activate the self-rewarding behavior through the striatum state (greendotted). This activates insula (orange) at $\mathrm{t} \approx 12$, indicating a self-thinking process. The self-thinking process, boosts the feelings of self-love $\mathrm{fs}_{\text {love }}$ (dark-brown) and self-reward $\mathrm{fs}_{\text {reward }}$ (pink), at time point $t \approx 10$. As a result, (s)he expresses gratitude, with such an expression.

\section{Reaction a negative feedback}

While observing a negative feedback of another person, a narcissist can react negative or extreme negative. Negative reactions may include an expression of sadness, fear, disgust, etc. While extreme negative reactions express negative feelings with a stronger intensity and can be expressed through anger, hostility, etc. (Ntshangase 2018). For example, let's consider another tweet of Trump, where he doesn't seem to feel pleasure from another peer, i.e.:

what kind of lawyer would tape a client? So sad! is this a first, never heard of it before? Why was the tape so abruptly (cut)....too bad (Tweeted: 2:34 PM - July 25, 2018).

Or, let's take an example like,

... world class loser, Tim O 'Brien, who I haven't seen or spoken ... knows NOTHING about me ... wrote a failed hit piece book... (Tweeted: 6:20 AM - Aug 8, 2019) (Folley 2019).

Figures 3 and 4, shows the simulation results. Certain behavior (e.g. videotaping and cutting in between without any notification) is evaluated as negative, thus eval-

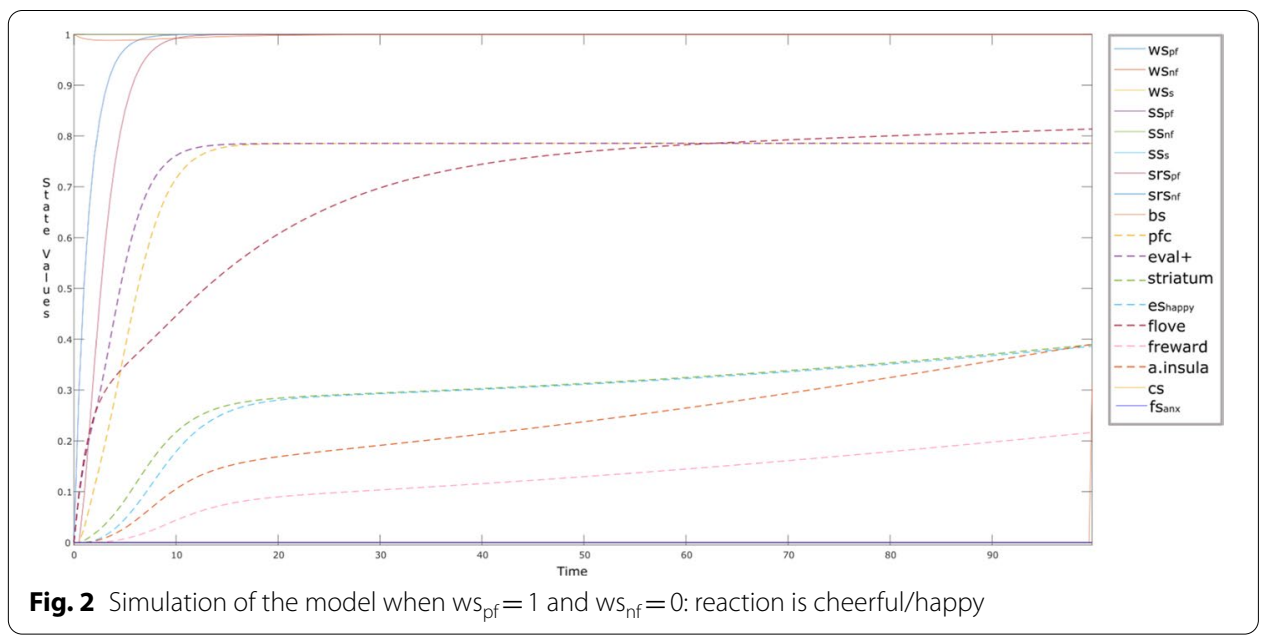



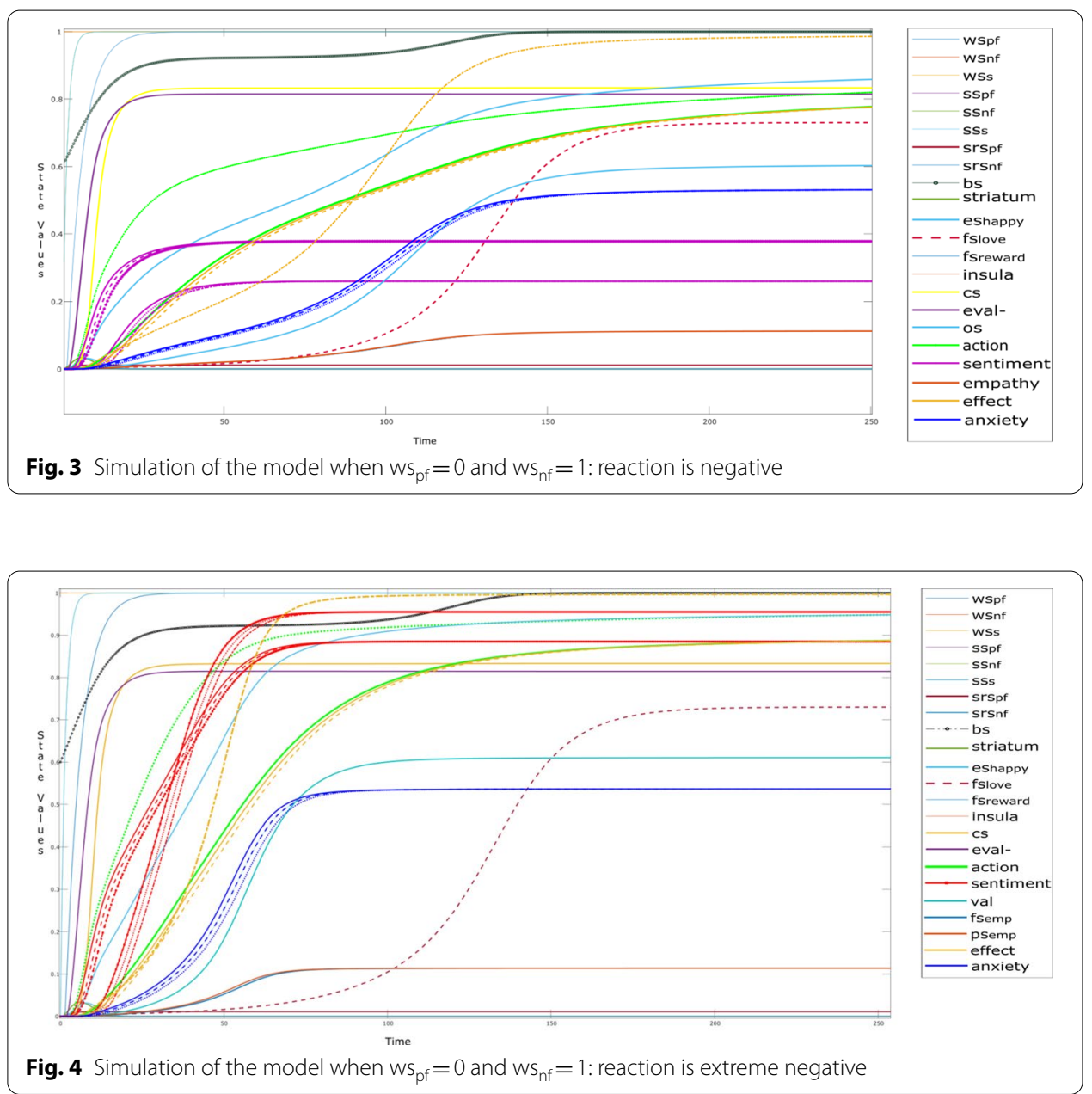

) gets activated at time point $t \approx 10-15$. This stimulates the negative sentiments $\left(\mathrm{fs}_{\text {sent }} \ldots, \mathrm{ps}_{\text {sent }}\right)$, along with the re-action states (bright green $\left.\longrightarrow: \mathrm{ps}_{\mathrm{act}} ; \mathrm{es}_{\mathrm{act}}\right)$ at $t \approx 20-25$. Also, the body loop of sentiments is activated ( $\mathrm{ws}_{\text {sent }} ; \mathrm{ss}_{\mathrm{sen}} ; \mathrm{srs}_{\mathrm{sent}} ; \mathrm{ps}_{\text {sent }} ;$ $\mathrm{fs}_{\text {sent }}$ and es sent $_{\text {clustered by }}$ ) around time point $t \approx 20$. This action provokes selfconscious behavior (os) on the basis of some past memories ( : $_{\mathrm{ws}_{\mathrm{eff}}} \mathrm{ss}_{\mathrm{eff}}$ and; $\mathrm{srs}_{\mathrm{eff}}$ ) resulting in anxiety ( $\mathrm{ws}_{\mathrm{anx}} ; \mathrm{ss}_{\mathrm{anx}} ; \mathrm{srs}_{\mathrm{anx}} ; \mathrm{fs}_{\mathrm{anx}}$; and $\mathrm{ps}_{\mathrm{anx}}$ : clustered by - ). As the person doesn't have empathy ( $\square$ : $\mathrm{ps}_{\mathrm{emp}}$ ), also anxiety intensifies the action (es ${ }_{\text {act }}$ ) state. Here, it can be observed, that although self-rewarding states are low (values $=0.03$ at time $t=0-10)$, the feeling of self-love $\mathrm{fs}_{\text {love }}(\boldsymbol{E}=$ ) continues to grow after $t=100$, intensifying the self-belief/ego (black dotted), indicating his love for himself only grows with the period of time. Figure 4 shows a similar behavior, with higher intensity shown by a body loop of sentiments in red. Here, it is to be noted that the reward related states like striatum (—) drops immediately at start $t=5-10$.

\section{Influence of popularity on reactions during feedback}

In this section, we address two behaviors of a narcissist: i.e. a) how (s)he reacts when (s) he is not popular and b) how does the popularity influence his/her behavior. 


\section{When the person is not popular}

"Reactions to feedback" section explains the reactions of a narcissist upon a positive or a negative feedback (Figs. 3, 4). Here, we combine them (Fig. 5), to address (a) behavior without popularity and (b) hebbian learning (described further in "Exhibition of learning experience in the model" section). Here, $\mathrm{ws}_{\mathrm{pop}}=0$, and the episodes with white background are the episodes whenever a positive feedback is observed, for example, the first episode has duration of time points $t=0-100$. In contrast, the episodes with colored background show the episodes with negative feedback, for example, during time points $t=100-200$. The length of duration and order of occurrences can be interchanged or overlapped, but for the purpose of simplicity, we kept them non-overlapping and with equal intervals. Interestingly, learning from different levels of intensities can be observed through two similar episodes. For example, negative response/action ( $=: \mathrm{ps}_{\mathrm{act}}$; $\left.\mathrm{es}_{\mathrm{act}}\right)$ in the earlier episodes is lower $(t=100-200)$ than the later episode $(t=300-400)$. Similarly, anxiety (_: $\left.\mathrm{ws}_{\mathrm{anx}} ; \mathrm{ss}_{\mathrm{anx}} ; \mathrm{srs}_{\mathrm{anx}} ; \mathrm{fs}_{\mathrm{anx}} ; \mathrm{ps}_{\mathrm{anx}}\right)$ also increases with each episode.

\section{When the person gains popularity}

Popularity is not earned overnight, but narcissists who aim to become social maven or influencers often choose tactics related to self-grandiosity and socialization. For example, they use social media to share their selfies and have a high number of likability and followers (Chua and Chang 2016; Folley 2019; Page 2012). Popularity influences the behaviors, and the symptoms related to depression (Nesi and Prinstein 2015), and anxiety are reduced (Trent 1957).

This ongoing process is shown in Fig. 6. For simplicity, only the important curves are presented in the figure. A person starts to earn popularity $\left(\varlimsup_{-}\right)$by sharing posts, at time point $t=450$. This popularity gain lowers the intensity of the negative feelings (fs sent $_{\text {: - - - }}$ es $_{\text {sent }}$ —, anxiety: — ity. Here it is to be noted that the popularity of a person is 0 for the minimum and 1 for the maximum.

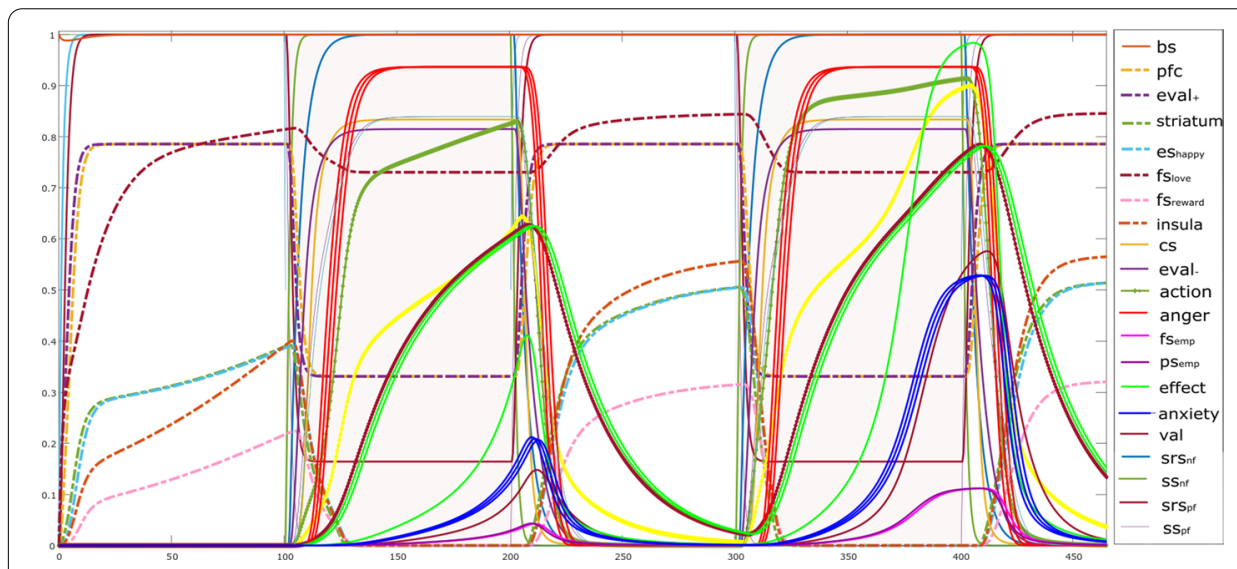

Fig. 5 Simulation of the model with alternative episodes of $\mathrm{ws}_{\mathrm{nf}}=1$ or $\mathrm{ws}_{\mathrm{pf}}=1$ : no popularity 

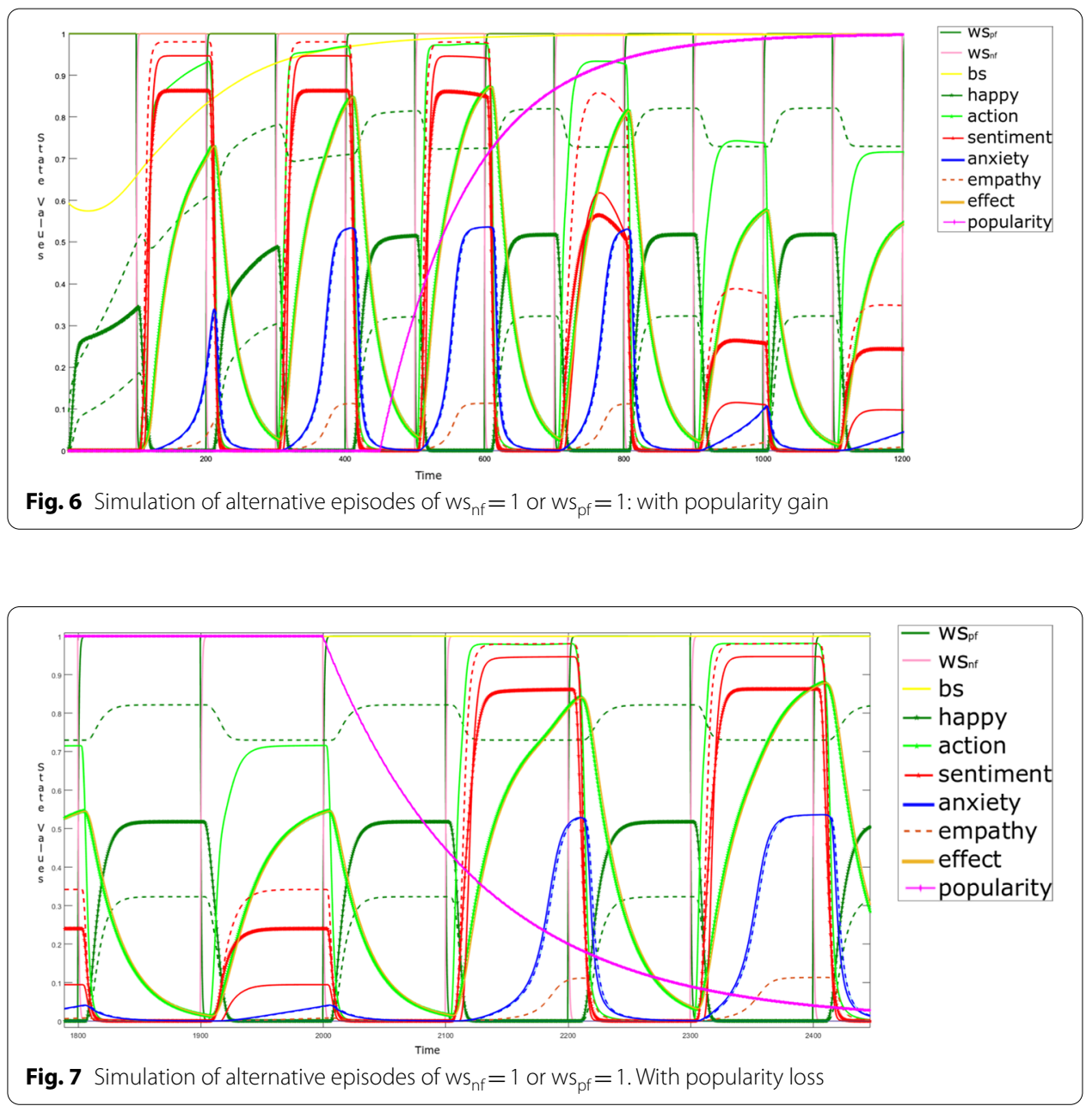

\section{When the person loses popularity}

Popularity is not static always, and it is natural that a person can gain/lose popularity over time. The reason can be variation of looks, trends, and so on (Polhemus 2011). As a result, narcissists' vulnerability may lead to negative reactions.

Figure 7 shows, when a person loses/tends to lose popularity, how different feedbacks can influence him/her. First, it can be observed in the duration of $t=1800-1900$, when a positive feedback is received $\left(\mathrm{ws}_{\mathrm{pf}}=1\right)$, the person feels rewarded and loved ( $\mathrm{fs}_{\text {love }}$ and $\mathrm{fs}_{\text {reward: }}$ - - -), so he is happy (es happy: - - ). However, in this scenario, his esteem (bs:

) and $\mathrm{fs}_{\text {love }}$ are already high, so there is no further learning in the self-rewarding behavior. The reason is that (s)he is aware of his/her self-worth. Second, when a disliking behavior or a critic is observed, (s)he flares up, which activates the negative sentiments (sentiment $=\mathrm{es}_{\text {sent }}$ : —; action $=\mathrm{es}_{\mathrm{act}}$ : —) and anxiety $(\longrightarrow)$ for $\mathrm{t}>2100$. Here, it is to be noted that predicted effect shows the same behavior due to hebbian learning of $\left(\mathrm{srs}_{\mathrm{eff}} \rightarrow \mathrm{ps}_{\mathrm{act}}\right)$.

\section{Exhibition of learning experience in the model}

In this section, we discuss the influence of hebbian learning on the Levels II and III. Previously, we saw the complex learning behavior over time (in episodes). For 


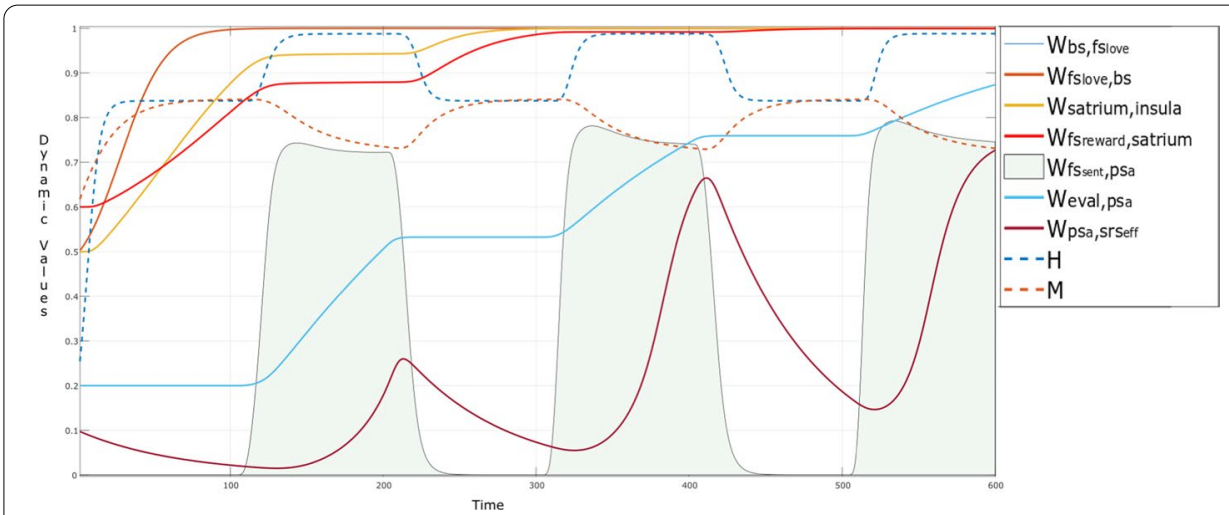

Fig. 8 Effects of plasticity (W states) and metaplasticity for $W_{f_{f_{s e n t}}, p_{a}}(M$ and $H)$

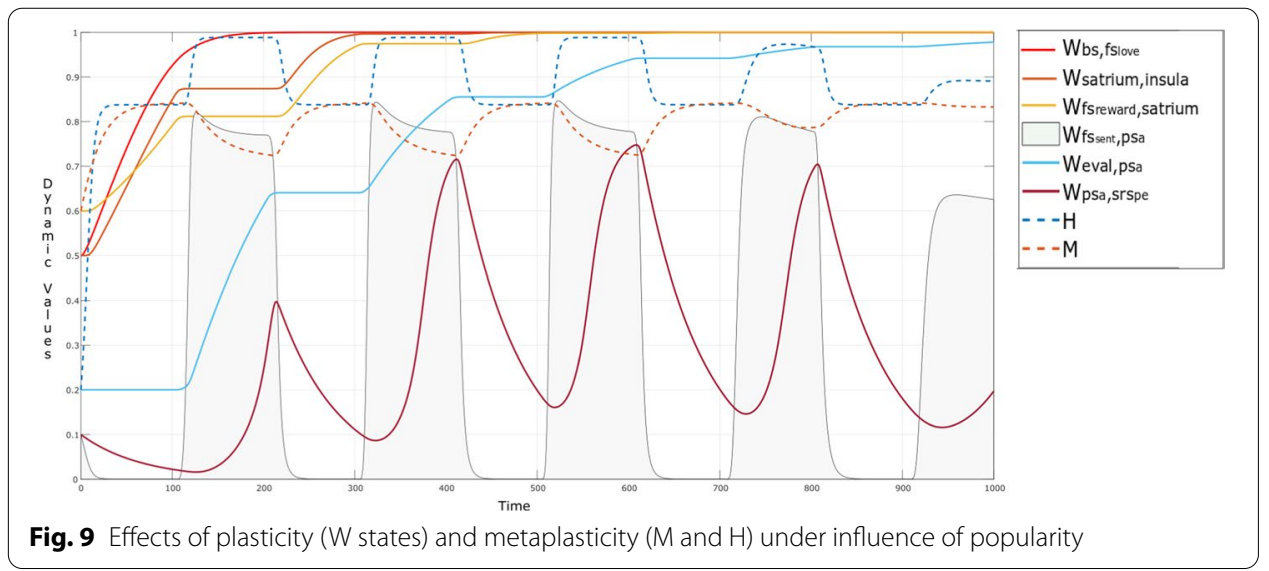

example, in the second episode of positive feedback $(t=200-300)$, the rewardrelated states (striatum, $\mathrm{fs}_{\text {reward }}$, $\mathrm{fs}_{\text {love }}$, insula) are elevated more than the first episode $(t=0-100)$ in Fig. 5. Similar behavior is observed when negative feedback is received. Here, we can observe the underlying behavior of hebbian learning (Fig. 8) at other levels: Level II for plasticity (W-states) and Level III for metaplasticity (M and $\mathbf{H}$ ). For example, consider $\mathbf{W}_{\text {eval-,psa }}$ (blue), the initial value of the state is 0.2 . During each negative episode the value is increased, so during $t=300$ to 400 the value is increased almost from 0.5 to 0.76 . Similarly, $\mathbf{W}_{\text {psa,srseff }}$ is raised compared to the previous episode showing the learning behavior (Sun et al. 2016). However, it can also be observed that due to metaplasticity, the state $\mathbf{W}_{\text {fssent,psa }}$ (colored background) was not much raised between two episodes due to $\mathbf{M}$ and $\mathbf{H}$ states (dotted) (Sun et al. 2016).

Figure 9 reflects how popularity influence states at Level II and Level III. Here, we can see that the learning in $\mathbf{W}$-states related to negative evaluation, action, and sentiments start to reduce after $t>450$. This is an effect of popularity gain, also we see same behavior for the metaplasticity-related states $\mathbf{M}$ and $\mathbf{H}$. This behavior would be vice versa when a person loses popularity. 


\section{Analysis of simulation experiments with reference to real-world data}

In this section, we analyze the behavior of our adaptive network model in relation to gathered empirical/real-world data. To accomplish this, we analysed thirty random public Instagram profiles, with presumably some extent of narcissistic traits, in line with literature such as (Chua and Chang 2016; Folley 2019; Page 2012). We compared the behaviors found there to our simulation experiments discussed in the previous section.

\section{Materials and methods}

Social media like Twitter or Instagram offer an environment where people tend to share their information, emotions and opinions to get feedback from others. We chose Instagram because: (1) its users have more tendency towards narcissism (Moon et al. 2016), and (2) different types of reactions can be observed in the form of conversations. These profiles were selected using the following criteria:

(1) the participants had at least shared 60 posts and

(2) they tend to share their selfies.

To examine the behavior of the model in correlation with the Instagram data, we used the following hypotheses through few key performance indicators (KPIs) were obtained (see Table 3):

(a) Narcissism/grandiose exhibition

1 Narcissistic people tend to share their selfies more frequently.

2 On appreciation, they feel happy and proud but react negatively otherwise.

Table $3 \mathrm{KPIs}$ to measures for popularity and narcissism along with their relevant literature

\begin{tabular}{|c|c|c|}
\hline KPI & Explanation & Reference \\
\hline \multicolumn{3}{|l|}{ Grandiose exhibition } \\
\hline selfiepm/otherpicspm & $\begin{array}{l}\text { How many selfie/other pictures shared } \\
\text { per month }\end{array}$ & $\begin{array}{l}\text { "Categories emerged ... on Instagram. } \\
\text { Personal promotion, brand promotion, } \\
\text { and sponsored promotion ... increase their } \\
\text { popularity... digital reputations" (Alshawaf } \\
\text { and Wen 2015) }\end{array}$ \\
\hline postfreqpm & Frequency of sharing posts per month & $\begin{array}{l}\text { "narcissists have more Facebook friends and } \\
\text { tend to post more provocative material" } \\
\text { (Bernarte et al. 2015) }\end{array}$ \\
\hline pconvsspm; nconvspm & $\begin{array}{l}\text { How many positive and negative conver- } \\
\text { sations per month }\end{array}$ & $\begin{array}{l}\text { "The relation between narcissism and disa- } \\
\text { greeableness increases when self-esteem is } \\
\text { taken into account" (Holtzman et al. 2010) }\end{array}$ \\
\hline \multicolumn{3}{|l|}{ Popularity } \\
\hline followerspm & How many followers per month & $\begin{array}{l}\text { "Instagram Leaders ... have more followers } \\
\text { than they are following" (Farwaha and } \\
\text { Obhi 2019; Utz et al. 2012) }\end{array}$ \\
\hline likespm & How many likes per month & $\begin{array}{c}\text { We chose the number of "likes" as the index of } \\
\text { popularity of a post (Zhang et al. 2018) }\end{array}$ \\
\hline htagspm & $\begin{array}{l}\text { Count the number of posts which had } \\
\text { one or more hashtags (boolean) }\end{array}$ & $\begin{array}{l}\text { "... use hashtags to make their professional } \\
\text { identity searchable ... promote their iden- } \\
\text { tity as affiliated.. wider professional field" } \\
\text { (Farwaha and Obhi 2019, p. 2012) }\end{array}$ \\
\hline
\end{tabular}


(b) Popularity

1 They gain popularity through particular behaviors, for example, self-presentation, or by using hashtags (Utz et al. 2012).

2 They have a high number of followers or friends (Utz et al. 2012)

3 More popularity can influence their behaviors:

(a) They engage more to seek admiration. (Paramboukis et al. 2016)

(b) Their depression/anxiety is reduced (Nesi and Prinstein 2015; Trent 1957).

Figure 10 briefly describes the algorithm used to formulate the results for the addressed KPIs. First, we extracted basic data of a profile from Instagram (steps 1-4). Second, we extracted data for each post in relation to its duration (5-7). Later, for every month, we extracted the posting frequency, the average number of likes, the selfie count, the number of posts which used hash tags, and the positive and negative conversations (8-13).

For selfie recognition, we used the KNN classifier with face encodings (Adam 2016) with the minimum threshold of 0.4. Moreover, for sentiment analysis, we used the combination of two classifiers: the IBM Watson tone analyzer and the Vader Sentiment Analyzer. The Watson tone analyzer was able to identify three types of sentiments: Cheerful, Negative, and Strong Negative. Cheerful emotions were related to happy/neutral reactions: joy, positive analytical. By positive analytical, we mean a neutral/positive discussion with an audience (maybe by telling a product name). This was computed by looking into the sentiment of the previous comment, and based upon its score, it was considered as a non-negative reply (as telling about herself and her products will make her feel happy about herself). The negative emotions were related to sadness or fear, while extreme negative meant anger, which is a negative feeling with stronger intensity (Ntshangase 2018). It can be an outcome of humiliation, annoyance or hostility. If the IBM Tone Analyzer does not detect any tone (for example, "Nice" without ".), theVader

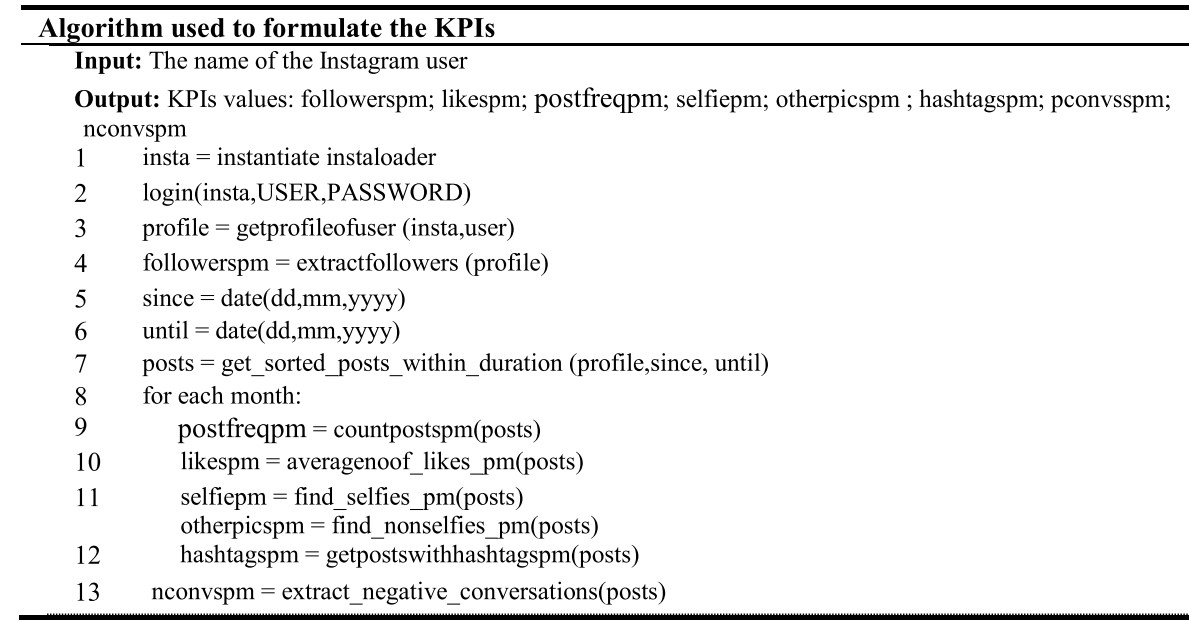

Fig. 10 Algorithm showing steps to extract data for KPIs 
Table 4 Three conversation examples with their sentiments

\begin{tabular}{lll}
\hline Type & Feedback/reply & Sentiment \\
\hline F1 & It looks hella face tuned & Neutral \\
R1 & you look hella negative & Negative \\
F2 & Well I think you look gorge! So happy for your family during this time & Joy \\
R2 & thank you! & Joy \\
F3 & You need to blend you highlight a bit more & Neutral \\
R3 & No I want to blind you so you piss off my page & Anger \\
\hline
\end{tabular}

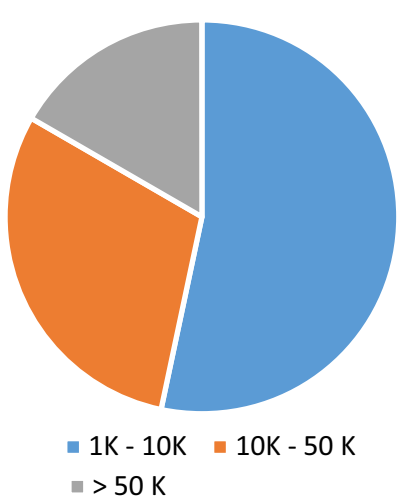

Fig. 11 Distribution of the participants of our study with respect to the number of followers

sentiment analyzer was used. It can detect three type of sentiments: positive, negative, and neutral (Hutto and Gilbert 2014), which were also used in our prior work (Jabeen et al. 2019). Table 4 shows some example conversations in terms of feedback ' $F$ ' and reply ' $R$ ', as analyzed by the Watson tone analyzer and the Vader sentiment analyzer.

\section{Results and discussion}

In this section, we will discuss our results from relevant to deviant cases in relation to the simulation experiments presented in "Simulation experiments" section. Each section will discuss the KPIs of popularity with reference to narcissism (Table 3), i.e.: (a) number of followers per month, (b) the average number of likes obtained per month, and (c) hashtag usage. The obtained results for all 30 considered profiles can be found in "Appendix B".

\section{Followers}

Different studies indicate 'followers to following ratio' (ff) and the number of followers (f) as a measure of popularity of a profile (Farwaha and Obhi 2019; Garcia et al. 2017). In our analysis, we used the current number of followers/and related trends to study behaviors in relation with popularity and narcissism. Therefore, we distributed the 30 extracted profiles in three groups with respect to the number of followers (Fig. 11). The first group consists of 5 of the 30 profiles (more than $50 \mathrm{~K}$ ), the second group had 9 profiles (between 10 and $50 \mathrm{~K}$ ), and our third group has 16 profiles (less than $10 \mathrm{~K}$ ). 
The collected data was analyzed using a measurement of time in months. It was observed that all users tend to post on a regular basis. As every profile tends to share different numbers of posts per month, so we took the average of posts per month, like posts/selfies per month by a user. It was observed that most participants tend to share more posts with selfies each month over a period of time (See "Appendix B" for the selfies ratio of each user). This can be an indication of self-love. For example: in Fig. 12, P3:CB has a high ratio of followers to following (followers: 262,000, following: 609), indicating this person is popular. Figure 12a shows a normalized distribution of the number of posts, average likes, hashtags, and followers per month. We can see an increase in posting frequency along with the average number of likes and number of followers. We can also see the trendlines indicating a linear increase in the average numbers of likes and the number of followers. This is also addressed by a user like:

I don't think that looks nice but the media say it was pretty, so people started following that and they got a lot of likes for it... (Chua and Chang 2016).

In Fig. 12b, we can see some correlation between sharing selfies and average likes and thus the number of followers in a month. High variations were also observed between the average number of selfies and the number of followers (see "Appendix B"). Therefore in "The average number of likes" section we will discuss our analysis with respect to the average likes as well.

During the conversation analysis, it was observed that 11 out of the 30 profiles actively responded to their followers. Figure 13 shows the distribution of participants with respect to their total response rate $\left(=\frac{\sum \text { conv }}{\text { totalposts }}\right)$, with values like:

$$
\text { Responserate }(p)= \begin{cases}\text { high } ; & \text { value } \geq 0.75 \\ \text { medium } ; & \text { value }>0.5 \text { and }<0.75 \\ \text { low } & \end{cases}
$$

On the one hand, it was observed that 5:14 users in the category of $<10 \mathrm{~K}$ followers, and 3:9 users in 10-50 K actively responded to their followers. While on the other hand in the

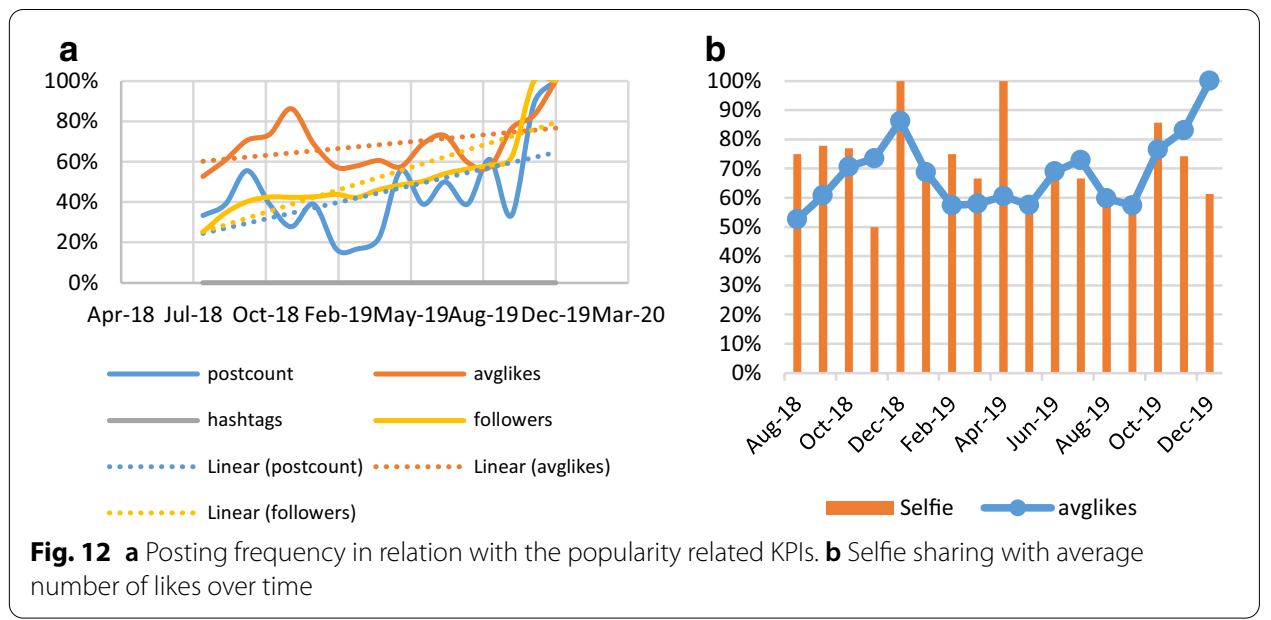




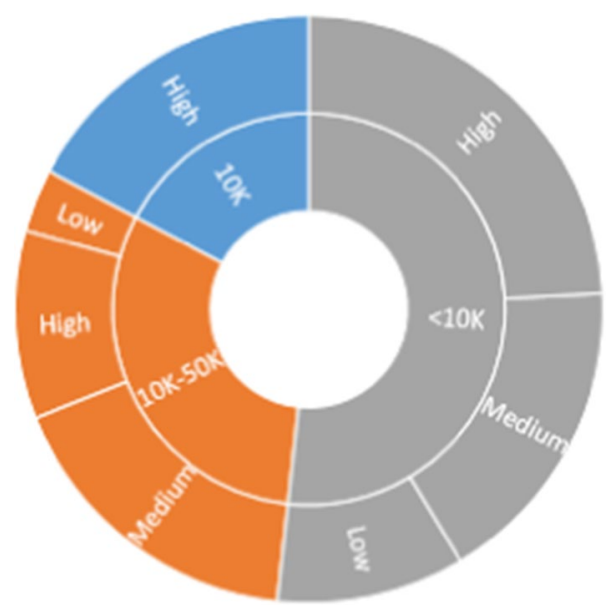

Fig. 13 Average responses per post with respect to the followers' distribution

more than $50 \mathrm{~K}$ category, all users (5:5) actively participated in conversations. In other words, 13 participants participated into the conversations more proactively (Bernarte et al. 2015).

An overall observation of conversations and sentiment analysis, people tend to respond more in a positive or neutral manner (Joy, positive analytical and Positive) than a negative manner (Anger, Fear, Sadness, Negative). Another interesting pattern was that most users with a low number of followers had more cheerful comments than negative ones. This truly doesn't relate to our simulations (i.e., negative behaviors have no/higher intensity with low/less popularity). However, we can assume that they didn't get critics most of the time, another possible reason can be to attract more followers or friends, or they were naïve on Instagram. With reference of the number of followers, there was no significant variation observed for negative or positive conversations (See "Appendix B").

\section{The average number of likes}

In this section, we analyze the behavior of Instagram users with respect to an increase/ decrease in the average number of likes. As per hypothesis, a user seeks the opportunity of self-promotion to get compliments or likes (Holtzman et al. 2010; Paramboukis et al. 2016; Zhang et al. 2018). As addressed by an Instagram user:

It makes me happy, ... I think, to me is you are cool, you're pretty, so you get a lot of likes. (Chua and Chang 2016).

In relation to grandiose self-exhibition, we looked into the selfie ratio, mostly it was observed, that participants have a higher tendency of getting likes if they share selfies (Fig. 12b; "Appendix B"). To investigate it further, we took each profile and computed the pearson correlation coefficient between the number of selfies and the average number of likes shared per month by: 


$$
\operatorname{corr}_{p}=\frac{\sum(\text { selfie }-\overline{\text { selfie }})(\text { likes }-\overline{\text { likes }})}{\sqrt{\sum(\text { selfie }-\overline{\text { selfie }})^{2} \sum(\text { likes }-\overline{\text { likes }})^{2}}}
$$

where $\operatorname{corr}_{p}=$ correlation value of a profile, $\overline{\text { selfie }}$ and $\overline{l i k e s}$ are the sample means of selfies and average number of likes in the duration of data collected.

It was observed that most of the profiles had a positive correlation between the two variables, however there were 6 out of 30 profiles, for which this correlation was low $(>-0.1)$. Figure 14 shows the distribution of users with respect to their relation/correlation values where:

$$
\text { relation }_{(\text {selfie,likes })}= \begin{cases}\text { high; } & \operatorname{corr}_{p}>0.5, \\ \text { medium } ; & \operatorname{corr}_{p}>0.3 \text { and }<0.5 \\ \text { low } ; & \operatorname{corr}_{p}<0.29\end{cases}
$$

Here, 12 users (40\%) showed a weak linear relationship, while 18 people showed moderate to strong positive relationships (moderate: 7; high: 11). This explains the behavior that people tend to share their selfies more often, as they may find this as an opportunity for approval and likability from their followers (Chua and Chang 2016).

While looking into the reactions of the users, we studied the extracted sentiments in the context of the average number of likes. Mostly, it was observed that in all profiles the users were mostly happy when they received more likes than otherwise. To make an explicit conclusion, we normalized each sentiment also in conversations. Therefore, a sentiment score per month was assigned through:

$$
\operatorname{sent}(t)=\frac{\text { sent_score }(t)}{\sum \text { sentiments }(t)}
$$

where sent_score $(t)=$ the individual score of a sentiment in a month $t$ and, $\sum$ sentiments $(t)=$ total sentiments found within a month $t \cdot \operatorname{sen} t(t)=$ a value of a sentiment in range of $[0,1]$.

Here, it is to be noted that possible sentiments are the cheerful (Joy/Positive, Positive Analytical, Neutral), the negative (Fear, Sadness, Negative) and the extreme negative (Anger) sentiments. For example, if in a month $t$, the sentiments of a user are: Joy $=2$, Sadness $=1$, and Negative $=1$, then sent_score for each in the month $t$ are: Joy $=0.5$,

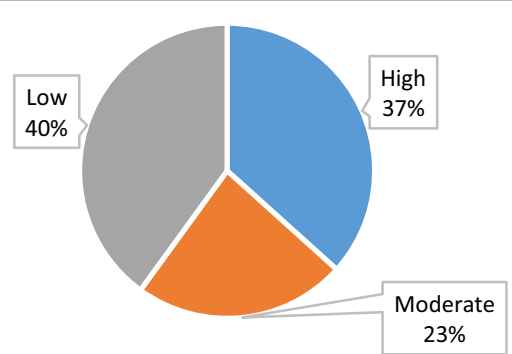

Fig. 14 Distribution of participants with respect to correlation values between selfies and average likes 
Sadness $=0.25$ and Negative $=0.25$. This implies that during conversations in month $t$, the user was $50 \%$ filled with 'Joy' and $25 \%$ for the rest of two. Similarly, we normalized the average number of likes for each month by dividing average likes obtained in a month by maximum likes received by a user in the duration of extracted data, resulting in a value between $[0,1]$.

We manually analyzed all profiles for the similarities and the differences, mostly positive conversations were observed showing personal satisfaction (Nesi and Prinstein 2015). However, in negative responses/reactions few interesting patterns were observed. For example in Fig. 15 when average number of likes of P2:LV are decreased (June 18, December 18, February 19 and so on) we can observe negative conversations (sadness: green, negative $=$ maroon or anger: silver). Also, positive conversations can be seen when (s)he gets more likes. A similar pattern can be observed for P24:LJ, P30: AB and so on ("Appendix B").

This can be considered as the behavior of a person being similar to the behavior we modeled in "Methods and methodologies and the obtained adaptive network model" section, shown in Fig. 1, (which models the reactions over a feedback as a cheerful response or a negative reply). Also, when a person gets popular (more average likes), then negative expressions are reduced. Here, it is to be noted that in February 18, there are few sudden drops in the average number of likes and conversations. This is possible, because this user did not share any post in this duration (Fig. 16).

For all profiles, we observed few variations in the behaviors in comparison to the designed model. However, here we use notion of 'most of the times' to generalize their behaviors. What we mean to say here is that although in August 18 P2:LV received more likes, we can still see some negative sentiments, but most of the time the person showed behavior similar to our model.

Table 5 enlists the profiles which reflected the indicated behavior most of the time, as well as the profiles which responded positively, and the rest which act more like outliers and show more variations from our simulation experiments. These fluctuating behaviors can be due to multiple reasons like: difference in personalities, their current popularity and time. For example, P10 or P20 seems to be less popular (less number of likes), during the whole time for which data was collected, resulting in fluctuating behavior.

We also tried to look through the patterns of hashtags, however, we were unable to see any patterns in relation to the behaviors, except most of the profiles used hashtags to

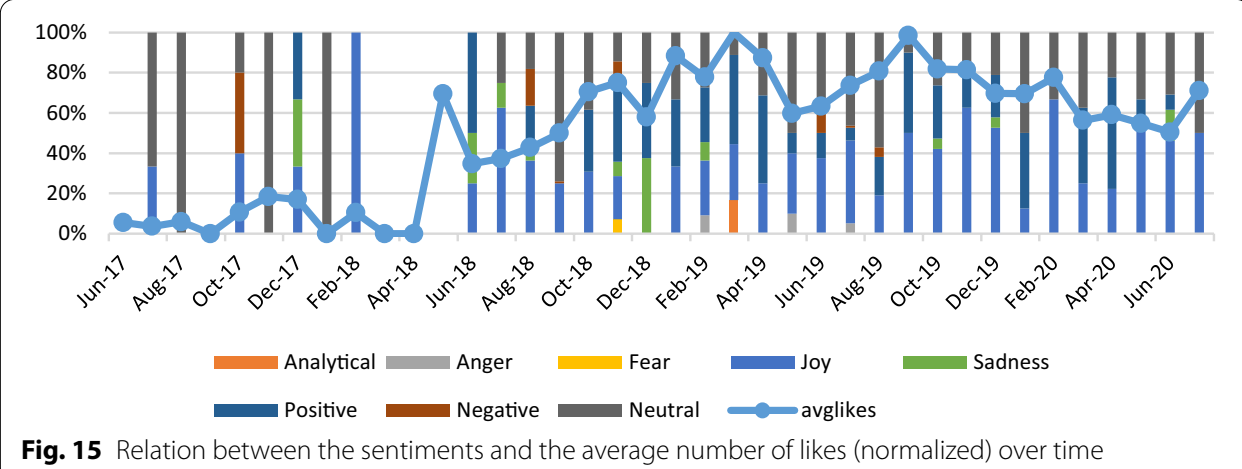




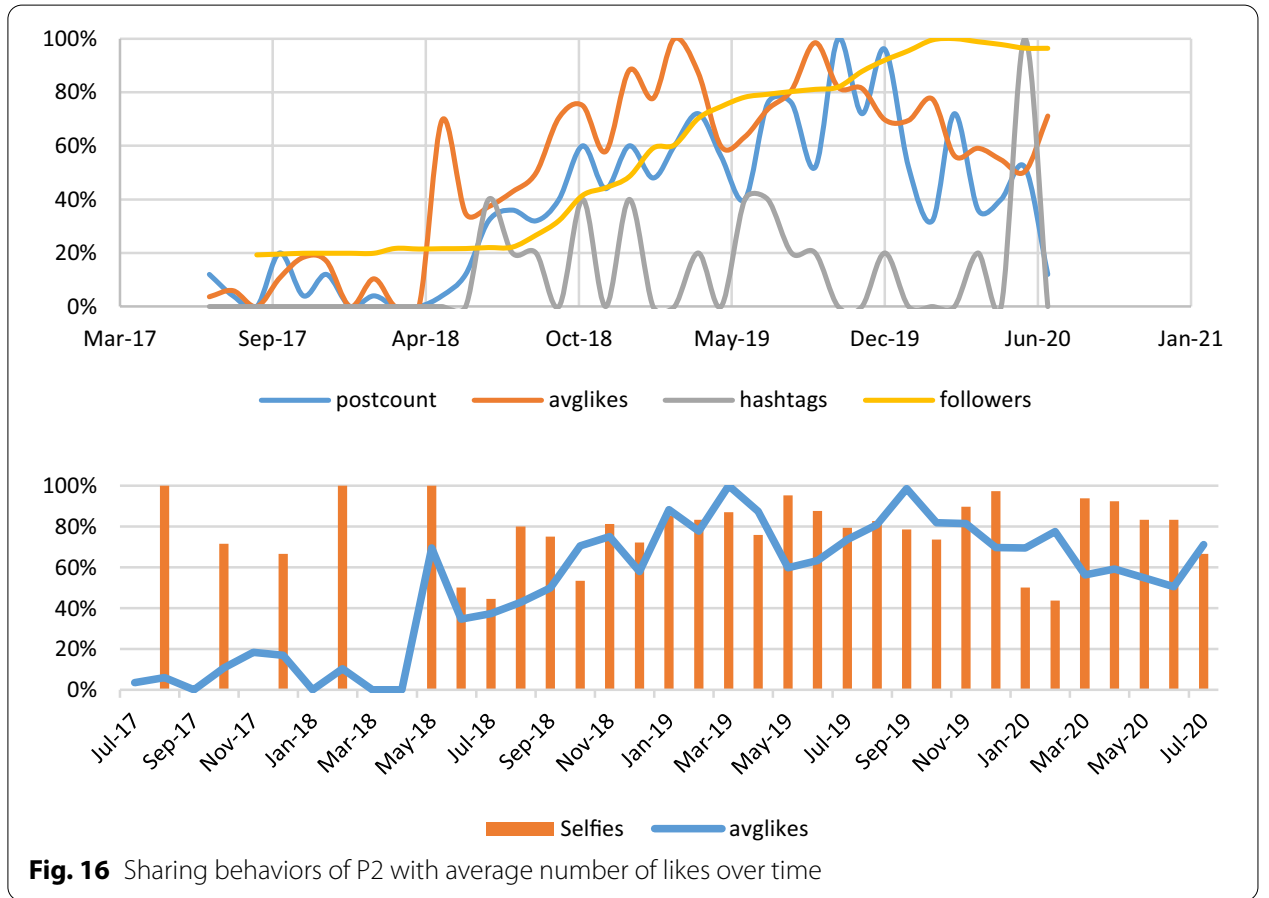

Table 5 Results showing which profiles are mostly aligned with the simulation results

\begin{tabular}{|c|c|c|c|c|c|c|c|c|c|}
\hline \multicolumn{3}{|c|}{ Aligned profiles } & \multicolumn{3}{|c|}{ Only positive profiles } & \multicolumn{3}{|c|}{ Non-aligned profiles } & \multirow[t]{2}{*}{ Total } \\
\hline P2 & P3 & P4 & P8 & P17 & P18 & P1 & P6 & P7 & \\
\hline P5 & P9 & P12 & P25 & P28 & & P10 & P11 & P13 & \\
\hline P15 & P16 & P24 & & & & P14 & P19 & P20 & \\
\hline \multirow[t]{2}{*}{ P27 } & P29 & P30 & & & & P21 & P22 & P23 & \\
\hline & & P26 & & & & & & & \\
\hline $12=40 \%$ & & & $5=16.66 \%$ & & & $13=43.33 \%$ & & & $30=100 \%$ \\
\hline
\end{tabular}

gain visibility. In conclusion from Table 5 , we saw that almost $60 \%$ of the profiles showed behaviors similar to our model, i.e. a narcissist is overwhelmed with joy when they get positive feedback and otherwise. Also, increase in popularity lead to happy reactions with a decrease in negative conversations. In "Limitations and future work" section, limitations and future work of the study are discussed.

\section{Limitations and future work}

The Watson analyzer is pretty accurate, also the Vader sentiment analysis gives a high accuracy in sentiment detection and classification (Hutto and Gilbert 2014). However, during the conduction of the study, it was observed that classifiers identified a few responses as negative, although they were positive ('fierce as fuck ') or ('fuck!! love you'). Although we adapted sentiment analysis as per needs of Instagram contents, though, it still can be validated further. Moreover, during selfie detection and analysis, many pictures that were taken from the back or were incomplete (without face), were categorized as others. Improvements in the two can help to improve the results and 
study further. We haven't used textual analysis approaches to study narcissism in the text, as they require natural language processing with longer texts, whereas in Instagram bibliography is known as the most long text, but it is not intended for this type of analysis. Also, we encountered messages which didn't have any text but just emojis like '

or '

Furthermore, in this study, almost all of the profiles in the dataset were presumed as narcissists. However, the authors didn't have their NPI scores or knew them personally. To make our work more concrete, it would be nice to investigate it more, for example, why do they have fluctuating behaviors and their relationship to the personality traits of a narcissist. So, as future work, we aim to set an experiment, which involves studying a person in relevance to his/her NPI score, sensitivity, and overall mood of a person to see this in relation to narcissism. This will help us to study behaviors with the understanding of narcissism in relation to personality traits in more detail. We also aim to study surrounding people like friends and family, who interact to a person with such behaviors.

\section{Conclusion}

In this paper, we presented a complex adaptive mental network model, which addresses the adaptive cognitive processes of a narcissist. Moreover, it explains his or her behavior and reactions, when (s)he receives positive or negative feedback. As his/her personality is vulnerable, an ego-threatening message is responded in a negative way, especially when popularity is low. In addition to our prior work, we saw how popularity can influence such a person's behavior. It was studied in how reward-seeking behavior blends with an increase in popularity, and the negative reactions are reduced. In order to compare our adaptive network model with empirical data, we extracted and analyzed data from 30 public profiles. Both from our simulation experiments and from the empirical analysis we observed that popularity acts as a moderator for a person with narcissistic traits. Thus our model indeed displays the real-world behavior of a narcissist, concerning the expression of emotion under the influence of increase/decrease in popularity.

In future work, we aim to incorporate different psychological measures like NPI score, sensitivity, or mood, to monitor narcissists. Moreover, we aim to design an automated system that can support a narcissist by counseling if he is highly vulnerable.

List of symbols and Abbreviations

Al: Artificial intelligence; GABA: $\gamma$-Aminobutyric acid; ACC: Anterior cingulate cortex; $\mu$; M: Persistence; Persistence Reification; $n$; H: Learning rate; Learning Rate reification; $\omega$; W: Connection weight; Connection weight Reification; $C_{y}$ : Combination function for a state $Y_{;} P_{i, j}$ Combination function parameter reification; ws: World state; ss: Sensory state; srs: Sensory representation state; fs: Feeling state; eval+: Positive evaluation; eval-: Negative evaluation; bs_: Belief state; striatum: Ventral striatum; PFC: Prefrontal cortex; es happy: Execution state of happiness; insula: Anterior insula; os: Ownership state; ps: Preparation state; es: Execution state; act: Action; pf: Positive feedback; nf: Negative feedback; anx: Anxiety; sent: Sen-

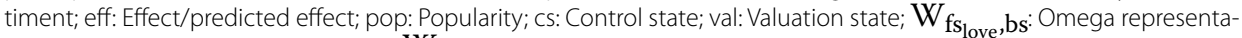

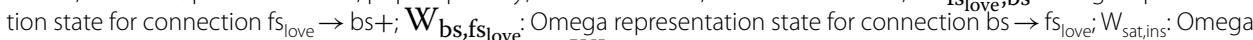
representation state for connection striatum $\rightarrow$ insula; $W_{\mathrm{fs}_{\text {rew }} \text {, striatum: }}$ Omega representation state for connection $\mathrm{fs}_{\text {reward }} \rightarrow$ striatum; $\mathrm{W}_{\text {eval-,ps }}$ : Omega representation state for connection eval $-\rightarrow \mathrm{ps}_{\text {acti }} ; \mathrm{W}_{\mathrm{ps}_{\text {act }} \text {,srs }}$ :ff: Omega rep-

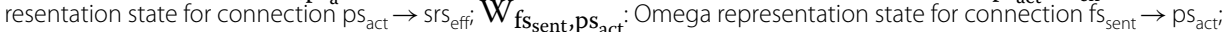
postfreqpm: Posting frequency behavior per month; likespm: Average number of likes per month; selfiepm: Number of selfies shared per month; otherpicspm: Number of other pictures per month; hashtagspm: Number of hashtags used per month; pconvspm: Positive conversations per month; nconvspm: Negative conversations per month; USER: User name to login; PASSWORD: User's password to login; KPI: Key Performance Indicators; w.r.t: With respect to.

\section{Acknowledgements}

The first author is grateful to Vrije Universiteit Amsterdam and University of the Punjab for providing the opportunities for research and successful completion of the study. 
This is an extended version of a paper (Jabeen et al. 2019) that appeared in Complex Networks'19. The new content of this article is a much larger empirical study and an additional focus on the influence of popularity on narcissism, presented along with the analysis of simulation experiments.

\section{Authors' contributions}

Fakhra Jabeen being a Ph.D. student presented the idea and completed the experiments and the project, while Dr. Charlotte Gerritsen and Prof. Dr. Jan Treur being supervisors, designed the study and helped towards completion of the project and producing the final manuscript of the paper. All authors read and approved the final manuscript.

Funding

Overseas scholarship from University of the Punjab, Lahore Pakistan.

Availability of data and materials

The data and materials used for analysis and development of results is available in https://github.com/MsFakhra/Mavens.

\section{Competing interests}

The authors declare that they have no competing interests.

\section{Appendix}

\section{A. Numerical relevance of the model}

The mathematical representation of a reified network architecture in terms of its network characteristics can be explained as follows (Treur 2020):

1 At every time point $t$, the activation level of state $Y$ at time $t$ is represented by $Y(t)$, with the values between $[0,1]$.

2 The single impact of state $X$ on state $Y$ at time $t$ is represented by $\operatorname{impact}_{X, Y}(t)=\omega_{X, Y}$ $X(t)$; where $\omega_{X, Y}$ is the weight of connection $X \rightarrow Y$. All single impacts for a given state $Y$ are aggregated by a combination function $\mathbf{c}_{Y}(.$.$) ; see below.$

3 Specific states are used to model specific types of network adaptation, where network characteristics such as connection weights and combination functions are dynamic. For example, $\mathbf{W}_{X, Y}$ represents an adaptive connection weight $\boldsymbol{\omega}_{X, Y}(\mathrm{t})$ for the connection $X \rightarrow Y$, while $\mathbf{H}_{Y}$ represents an adaptive speed factor $\boldsymbol{\eta}_{Y}(\mathbf{t})$ of state $Y$. Similarly, $\mathbf{C}_{i, Y}$ and $\mathbf{P}_{i, j, Y}$ represent adaptive combination functions $\mathbf{c}_{Y}(. ., t)$ over time and their parameters, respectively. Combination functions are built as a weighted average from a number of basic combination functions $\operatorname{bcf}_{i}(.$.$) from a library, which take parame-$ ters $P_{i, j, Y}$ and values $V_{i}$ as arguments. For adaptive network models in which network characteristics are dynamic as well, the universal combination function $\mathbf{c}^{*}{ }_{Y}(.$.$) used$ for any state $Y$ is defined as:

$$
\begin{aligned}
\mathbf{c}_{Y}^{*}\left(S, C_{1}, \ldots, C_{m}, P_{1,1}, P_{2,1}, \ldots, P_{1, m}, P_{2, m}, V_{1}, \ldots, V_{k}, W_{1}, \ldots, W_{k}, W\right) \\
=W+S\left[C_{1} \operatorname{bcf}_{1}\left(P_{1,1}, P_{2,1}, W_{1} V_{1}, \ldots, W_{k} V_{k}\right)\right. \\
\left.\left.\quad+\cdots+C_{m} \operatorname{bcf}_{m}\left(P_{1, m}, P_{2, m}, W_{1} V_{1}, \ldots, W_{k} V_{k}\right)\right] /\left(C_{1}+\cdots+C_{m}\right)-W\right]
\end{aligned}
$$

where at time $t$ :

- variable $S$ is used for the speed factor reification $\mathbf{H}_{Y}(t)$

- variable $C_{i}$ for the combination function weight reification $\mathbf{C}_{i, Y}(t)$

- variable $P_{i, j}$ for the combination function parameter reification $\mathbf{P}_{i, j, Y}(t)$

- variable $V_{i}$ for the state value $X_{i}(t)$ of base state $X_{i}$

- variable $W_{i}$ for the connection weight reification $\mathbf{W}_{X i, Y}(t)$

- variable $W$ for the state value $Y(t)$ of base state $Y$. 
4. Based on the above universal combination function, the effect on any state $Y$ after time $\Delta t$ is computed by the following universal difference equation as:

$$
\begin{aligned}
\mathbf{Y}(\mathbf{t}+\boldsymbol{\Delta t})= & Y(t)+\left[\mathbf { c } ^ { * } { } _ { Y } \left(\mathbf{H}_{Y}(t), \mathbf{C}_{1, Y}(t), \ldots, \mathbf{C}_{m, Y}(t), \mathbf{P}_{1,1}(t), \mathbf{P}_{2,1}(t), \ldots,\right.\right. \\
& \left.\left.\mathbf{P}_{1, m}(t), \mathbf{P}_{2, m}(t), X_{1}(t), \ldots, X_{k}(t), \mathbf{W}_{X_{1}, Y}(t), \ldots, \mathbf{W}_{X_{k}, Y}(t), Y(t)\right)-Y(t)\right] \Delta t
\end{aligned}
$$

which also can be written as a universal differential equation:

$$
\begin{aligned}
\mathbf{d} Y(t) / \mathbf{d} t= & \mathbf{c}^{*}{ }_{Y}\left(\mathbf{H}_{Y}(t), \mathbf{C}_{1, Y}(t), \ldots, \mathbf{C}_{m, Y}(t), \mathbf{P}_{1,1}(t), \mathbf{P}_{2,1}(t), \ldots,\right. \\
& \left.\mathbf{P}_{1, m}(t), \mathbf{P}_{2, m}(t), X_{1}(t), \ldots, X_{k}(t), \mathbf{W}_{X_{1}, Y}(t), \ldots, \mathbf{W}_{X_{k}, Y}(t), Y(t)\right)-Y(t)
\end{aligned}
$$

\section{B. Dataset}

The large table below enlists the data collected from the 30 Instagram profiles. The first and the third column have the information like the profile ID, their name initials, their number of followers ( $f$ ) and current followers to following ratio $(f / f)$. Here it is to be noted that to keep the anonymity of results, each profile is assigned ID in a pattern like PXX. The second and fourth column consist of the increase/decrease in frequency.

a of posts, followers, average number of likes and hash tags

b ratio between selfies and other pictures

c sentiments related variations

These data were extracted and studied over a period of time for each profile s indicated. Note that this compares to simulation results for the model designed in "Methods and methodologies and the obtained adaptive network model" section aiming at a single person and his/her related behavior.

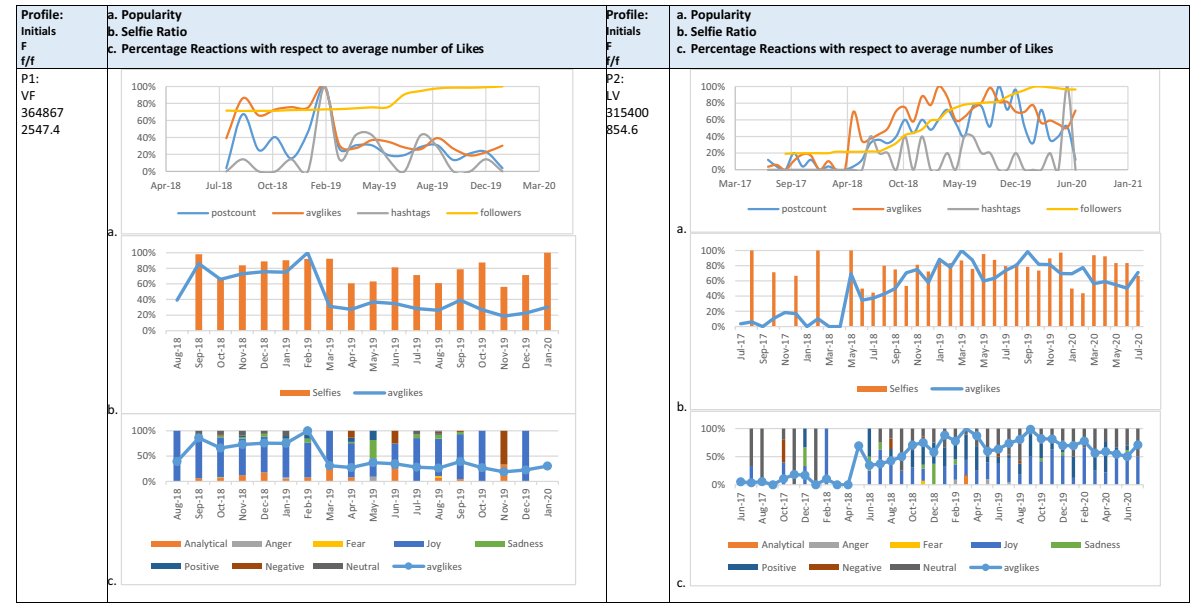



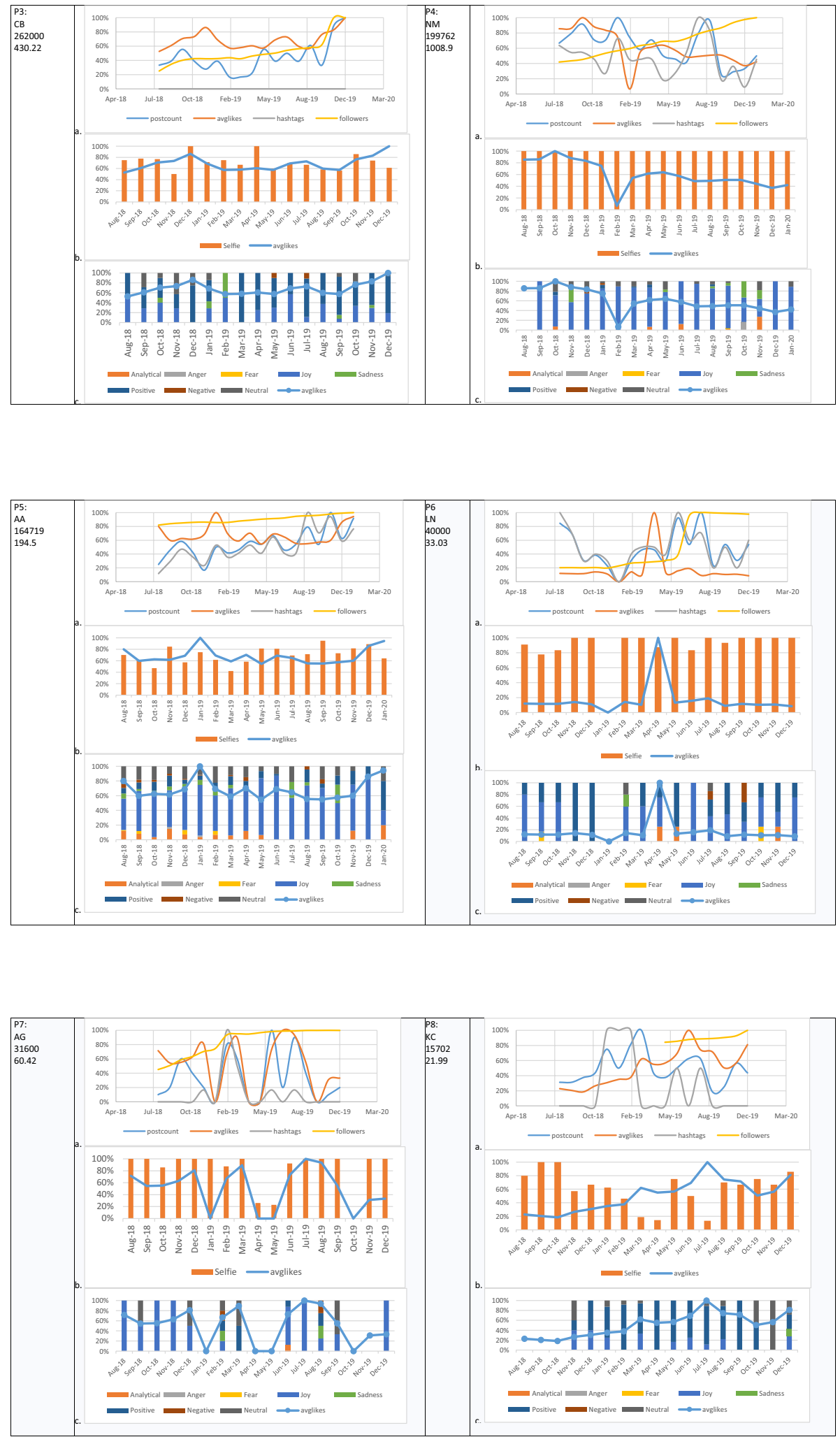

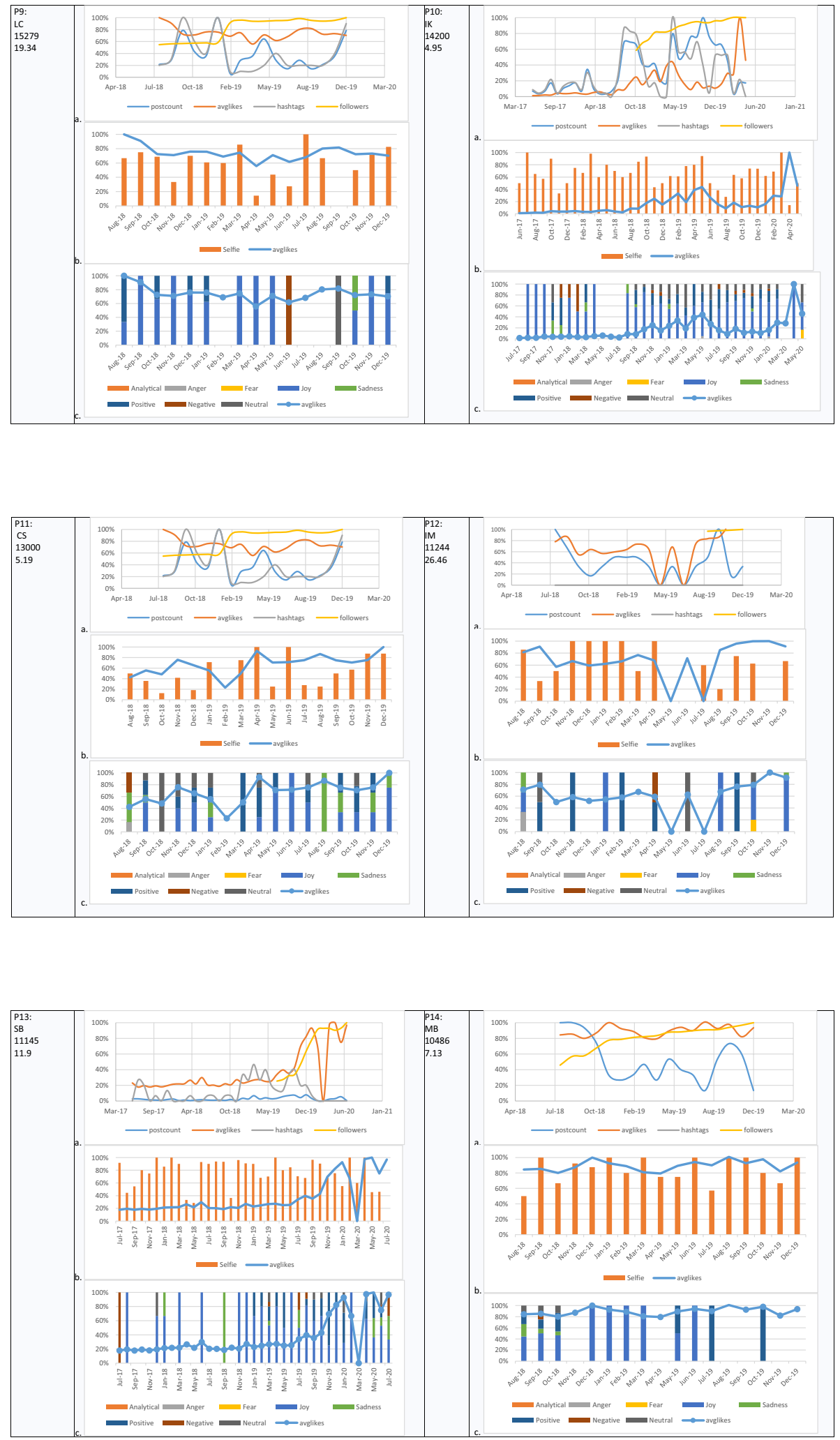

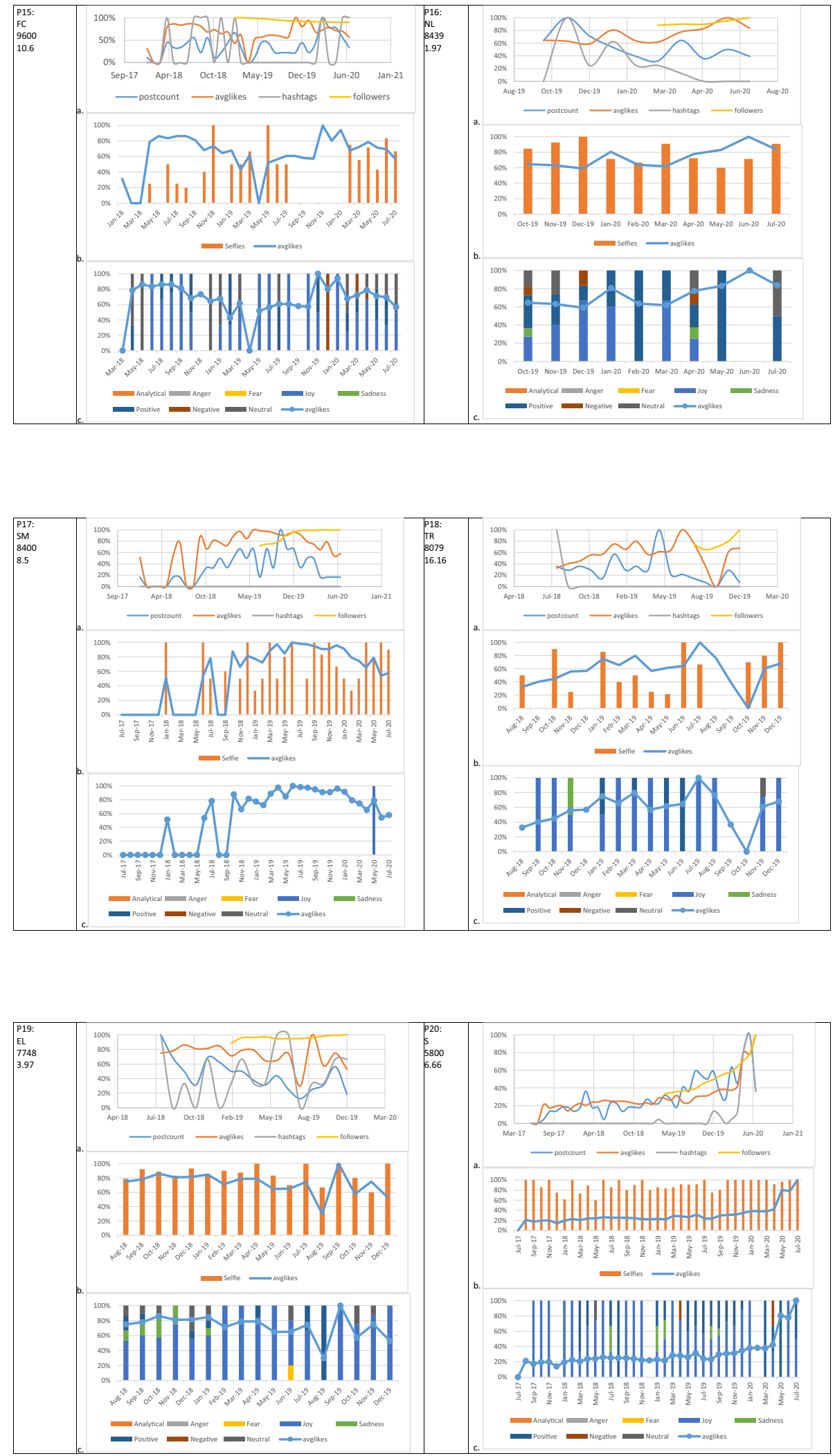

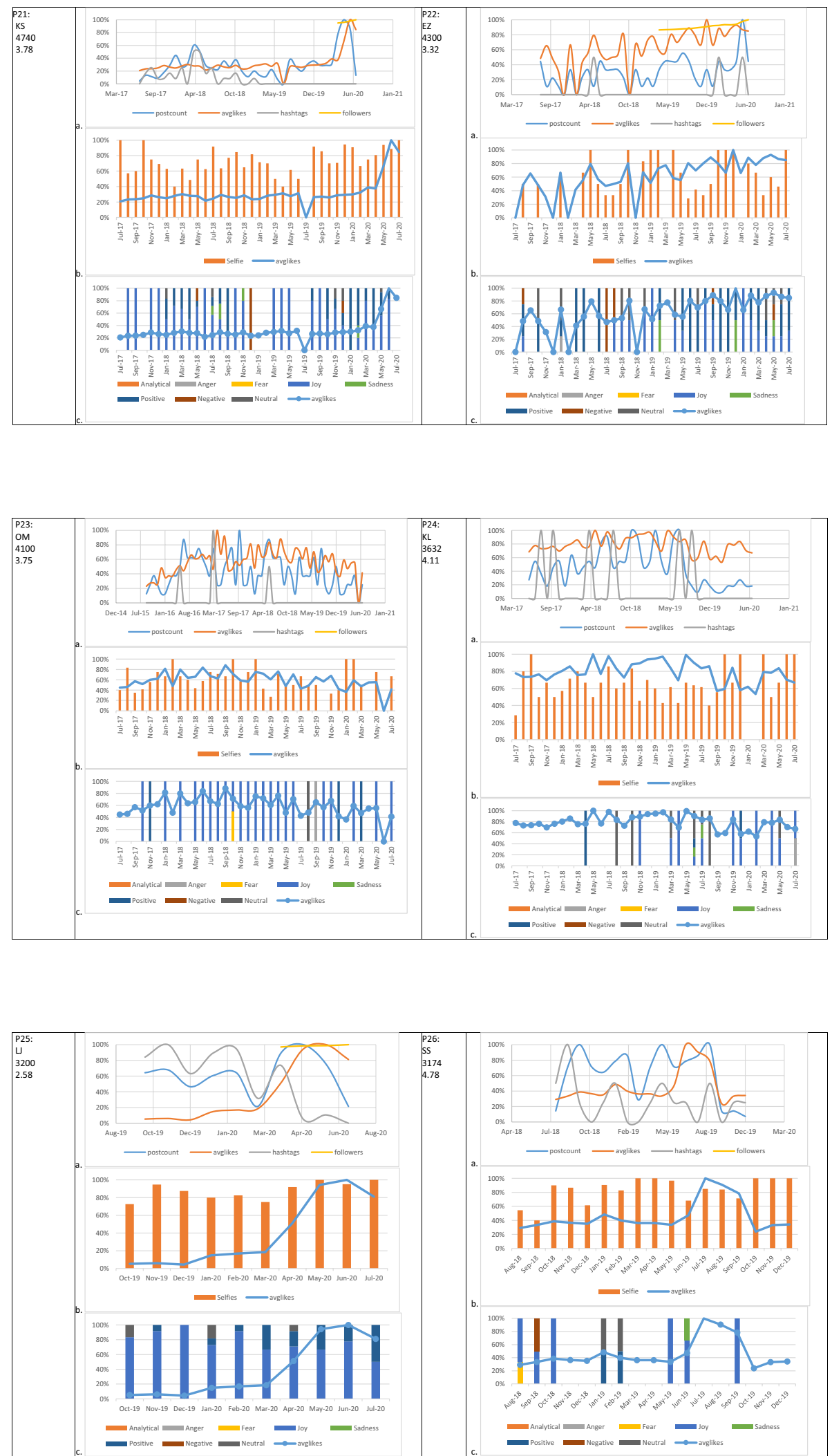

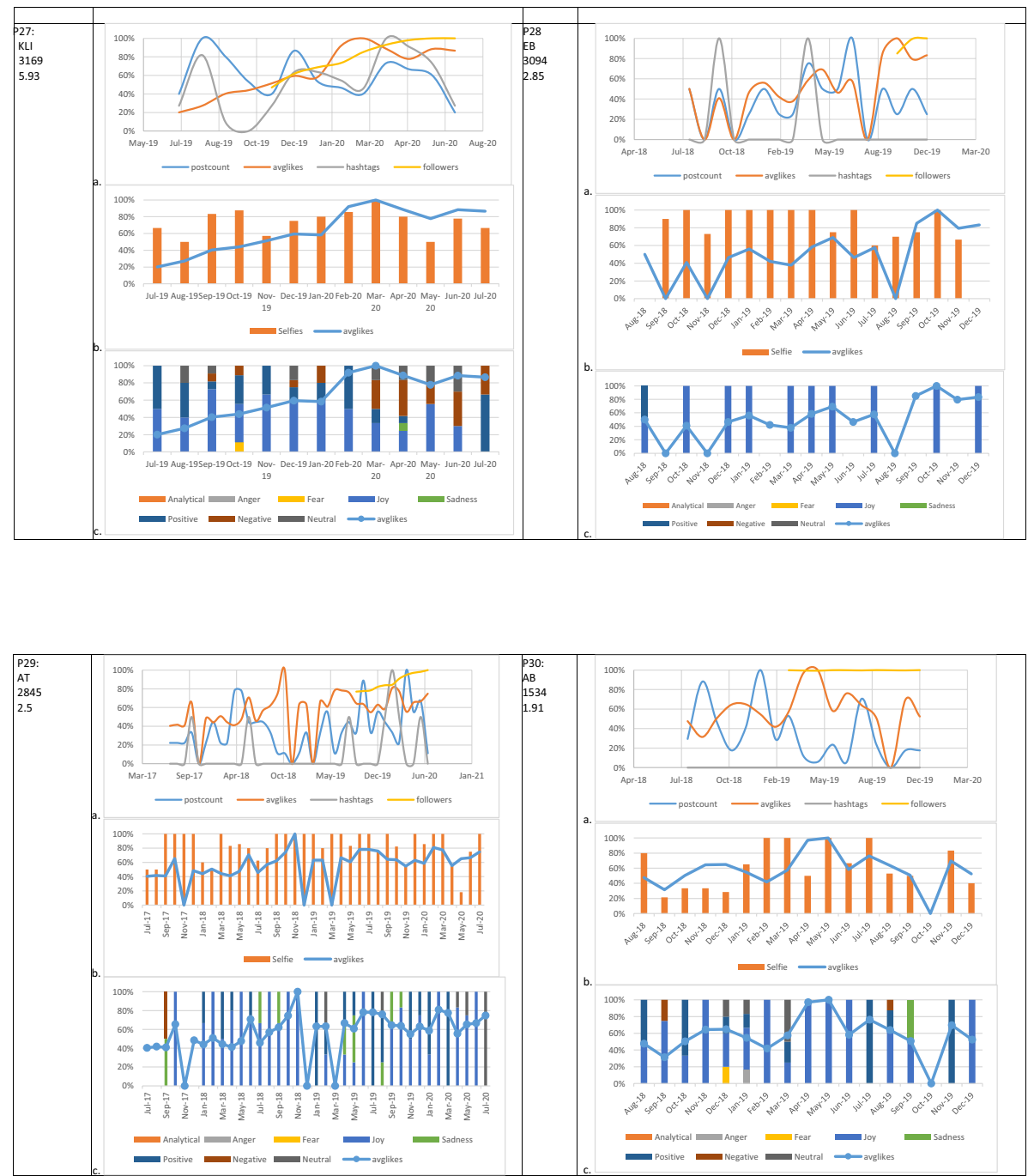

Received: 8 April 2020 Accepted: 7 October 2020

Published online: 31 October 2020

\section{References}

Adam G (2016) Face_Recognition. https://github.com/ageitgey/face_recognition. Accessed July 2020

Alshawaf E, Wen L (2015) Understanding digital reputation on Instagram: a case study of social media mavens. In: Proceedings of the 2nd European conference on social media ECSM, pp 19-27

Bernarte RP, Festijo Al, Layaban MD, Ortiz SU (2015) Me, myself and i: What makes filipino millennials narcissist? Asia Pac Higher Educ Res J (APHERJ) 2(1)

Brummelman E, Thomaes S, Nelemans SA, Orobio de Castro B, Overbeek G, Bushman BJ (2015) Origins of narcissism in children. Proc Natl Acad Sci 112(12):3659-3662. https://doi.org/10.1073/pnas.1420870112

Bushman BJ, Baumeister RF (1998) Threatened egotism, narcissism, self-esteem, and direct and displaced aggression: does self-love or self-hate lead to violence? J Pers Soc Psychol. https://doi.org/10.1037/e552692012-026

Chua THH, Chang L (2016) Follow me and like my beautiful selfies: Singapore teenage girls' engagement in selfpresentation and peer comparison on social media. Comput Hum Behav 55:190-197. https://doi.org/10.1016/j. chb.2015.09.011 
Damasio AR (2012) Self comes to mind: constructing the conscious brain. Vintage, New York. https://doi. org/10.1080/13546805.2011.648756

Daniel R, Pollmann S (2014) A universal role of the ventral striatum in reward-based learning: evidence from human studies. Neurobiol Learn Mem 114:90-100. https://doi.org/10.1016/..n/m.2014.05.002

de Almeida RMM, Cabral JCC, Narvaes R (2015) Behavioural, hormonal and neurobiological mechanisms of aggressive behaviour in human and nonhuman primates. Physiol Behav 143:121-135. https://doi.org/10.1016/j.physb eh.2015.02.053

Elliott M (2002) Bullying: a practical guide to coping for schools. Pearson Education

Fan Y, Wonneberger C, Enzi B, de Greck M, Ulrich C, Tempelmann C, Bogerts B, Doering S, Northoff G (2011) The narcissistic self and its psychological and neural correlates: an exploratory fMRI study. Psychol Med 41(8):16411650. https://doi.org/10.1017/S003329171000228X

Fan C, Chu X, Zhang M, Zhou Z (2019) Are narcissists more likely to be involved in cyberbullying? Examining the mediating role of self-esteem. J Interpers Violence. https://doi.org/10.1177/0886260516666531

Farwaha S, Obhi SS (2019) Differential motor facilitation during action observation in followers and leaders on instagram. Front Hum Neurosci 13:67. https://doi.org/10.3389/fnhum.2019.00067

Folley A (2019) Trump rips MSNBC, CNN for inviting guests who 'have no idea what I am all about'

Garcia D, Mavrodiev P, Casati D, Schweitzer F (2017) Understanding popularity, reputation, and social influence in the twitter society: understanding the twitter society. Policy Internet 9(3):343-364. https://doi.org/10.1002/poi3.151

Holtzman NS, Vazire S, Mehl MR (2010) Sounds like a narcissist: behavioral manifestations of narcissism in everyday life. J Res Pers 44(4):478-484. https://doi.org/10.1016/j.jrp.2010.06.001

Holtzman NS, Tackman AM, Carey AL, Brucks MS, Küfner AC, Deters FG, Back MD, Donnellan MB, Pennebaker JW, Sherman RA, Mehl MR (2019) Linguistic markers of grandiose narcissism: A LIWC analysis of 15 samples. J Lang Soc Psychol 38(5-6):773-786. https://doi.org/10.31234/osf.io/aeuzk

Hutto CJ, Gilbert E (2014) Vader: a parsimonious rule-based model for sentiment analysis of social media text. In: AAAI conference on weblogs and social media

Jabeen F (2020) Maven specifications. Role matrices. https://github.com/MsFakhra/Mavens. Accessed July 2020

Jabeen F, Gerritsen C, Treur J (2019) II ain't like you'A complex network model of digital narcissism. In: International conference on complex networks and their applications, pp 337-349. https://doi.org/10.1007/978-3-030-36683 -4 -28

Jauk E, Benedek M, Koschutnig K, Kedia G, Neubauer AC (2017) Self-viewing is associated with negative affect rather than reward in highly narcissistic men: an fMRI study. Sci Rep. https://doi.org/10.1038/s41598-017-03935-y

McCain JL, Campbell WK (2018) Narcissism and social media use: a meta-analytic review. Psychol Pop Media Culture 7(3):308. https://doi.org/10.1037/ppm0000137

Moon JH, Lee E, Lee J-A, Choi TR, Sung Y (2016) The role of narcissism in self-promotion on Instagram. Personal Individ Differ 101:22-25. https://doi.org/10.1016/j.paid.2016.05.042

Nai A (2019) Disagreeable narcissists, extroverted psychopaths, and elections: a new dataset to measure the personality of candidates worldwide. Eur Polit Sci 18(2):309-334. https://doi.org/10.1057/s41304-018-0187-2

Nesi J, Prinstein MJ (2015) Using social media for social comparison and feedback-seeking: gender and popularity moderate associations with depressive symptoms. J Abnorm Child Psychol 43(8):1427-1438. https://doi. org/10.1007/s10802-015-0020-0

Neuman Y (2016) Computational personality analysis: Introduction, practical applications and novel directions (First). Springe, Berlin

Ntshangase T (2018) IBM tone-analyzer score board. https://developer.ibm.com/code/2018/02/21/tone-analyzerservice-ibm-cloud/

Olsson J, Berglund S, Annett J (2014) Narcissism — brain and behavior: self-views and empathy in the narcissistic brain, pp 45

Page R (2012) The linguistics of self-branding and micro-celebrity in Twitter: the role of hashtags. Discourse Commun 6(2):181-201. https://doi.org/10.1177/1750481312437441

Panek ET, Nardis Y, Konrath S (2013) Mirror or Megaphone?: How relationships between narcissism and social networking site use differ on Facebook and Twitter. Comput Hum Behav 29(5):2004-2012. https://doi.org/10.1016/j. chb.2013.04.012

Paramboukis O, Skues J, Wise L (2016) An exploratory study of the relationships between narcissism, self-esteem and instagram use. Soc Netw 05(02):82-92. https://doi.org/10.4236/sn.2016.52009

Polhemus T (2011) Fashion and anti-fashion. Lulu.com

Raghunathan R, Pham MT (1999) All negative moods are not equal: Motivational influences of anxiety and sadness on decision making. Organ Behav Hum Decis Process 79(1):56-77. https://doi.org/10.1006/obhd.1999.2838

Robinson BL, Harper NS, MCAlpine D (2016) Meta-adaptation in the auditory midbrain under cortical influence. Nat Commun 7(1):13442. https://doi.org/10.1038/ncomms13442

Scheines R, Spirtes P, Glymour C (1991) A qualitative approach to causal modeling. In: Fishwick PA, Luker PA (eds) Qualitative simulation modeling and analysis. Springer, Berlin, pp 72-97. https://doi. org/10.1007/978-1-4613-9072-5_4

Schmidt MV, Abraham WC, Maroun M, Stork O, Richter-Levin G (2013) Stress-induced metaplasticity: from synapses to behavior. Neuroscience 250:112-120. https://doi.org/10.1016/j.neuroscience.2013.06.059

Sun P, Wei S, Wei X, Wang J, Zhang Y, Qiao M, Wu J (2016) Anger emotional stress influences VEGF/VEGFR2 and its induced PI3K/AKT/mTOR signaling pathway. Neural Plast 2016:1-12. https://doi.org/10.1155/2016/4129015

Trent RD (1957) The relationship of anxiety to popularity and rejection among institutionalized delinquent boys. Child Dev. https://doi.org/10.2307/1126197

Treur J (2020) Network-oriented modeling for adaptive networks: designing higher-order adaptive biological, mental and social network models, vol 251. Springer, Berlin. https://doi.org/10.1007/978-3-030-31445-3

Utz S, Tanis M, Vermeulen I (2012) It is all about being popular: the effects of need for popularity on social network site use. Cyberpsychol Behav Soc Netw 15(1):37-42. https://doi.org/10.1089/cyber.2010.0651 
Wang D (2017) A study of the relationship between narcissism, extraversion, drive for entertainment, and narcissistic behavior on social networking sites. Comput Hum Behav 66:138-148. https://doi.org/10.1016/j.chb.2016.09.036

Weger M, Sandi C (2018) High anxiety trait: a vulnerable phenotype for stress-induced depression. Neurosci Biobehav Rev 87:27-37. https://doi.org/10.1016/j.neubiorev.2018.01.012

Zhang Z, Chen T, Zhou Z, Li J, Luo J (2018) How to become Instagram famous: post popularity prediction with dualattention. In: 2018 IEEE international conference on big data (big data), pp 2383-2392. https://doi.org/10.1109/ bigdata.2018.862246

\section{Publisher's Note}

Springer Nature remains neutral with regard to jurisdictional claims in published maps and institutional affiliations.

Submit your manuscript to a SpringerOpen ${ }^{\circ}$ journal and benefit from:

- Convenient online submission

- Rigorous peer review

- Open access: articles freely available online

High visibility within the field

- Retaining the copyright to your article

Submit your next manuscript at $>$ springeropen.com 